\title{
Outcomes associated with the use of microprocessor-controlled prosthetic knees among individuals with unilateral transfemoral limb loss: A systematic review
}

\author{
Andrew B. Sawers, MSPO, CPO; ${ }^{1-2 *}$ Brian J. Hafner, PhD ${ }^{2}$ \\ ${ }^{1}$ Rehabilitation Research and Development Center of Excellence for Limb Loss Prevention and Prosthetic Engineering, \\ Department of Veterans Affairs Puget Sound Health Care System, Seattle, WA; ${ }^{2}$ Department of Rehabilitation Medicine, \\ University of Washington, Seattle, WA
}

\begin{abstract}
Microprocessor-controlled prosthetic knees (MPKs) have been developed as an alternative to non-microprocessorcontrolled knees (NMPKs) to address challenges facing individuals with lower-limb loss. A body of scientific literature comparing MPKs and NMPKs exists but has yet to be critically appraised. Therefore, we conducted a systematic review to examine outcomes associated with the use of these interventions among individuals with transfemoral limb loss. A search of biomedical databases identified 241 publications, of which 27 met the inclusion and exclusion criteria and were reviewed for methodological quality and content. We developed 28 empirical evidence statements (EESs) in 9 outcome categories (metabolic energy expenditure, activity, cognitive demand, gait mechanics, environmental obstacle negotiation, safety, preference and satisfaction, economics, and health and quality of life) based on findings in the literature. The level of evidence supporting these EESs varied due to quantity, quality, and consistency of the results. EESs supported by a moderate level of evidence that noted significant differences between MPKs and NMPKs were derived in five of the nine outcome categories. The results from this review suggest that evidence exists to inform clinical practice and that additional research is needed to confirm existing evidence and better understand outcomes associated with the use of NMPKs and MPKs.
\end{abstract}

Key words: amputation, artificial limb, function, gait, knee, microprocessor, outcome, preference, rehabilitation, safety.
Abbreviations: $\mathrm{AAOP}=$ American Academy of Orthotists and Prosthetists, $\mathrm{ABC}=$ Activities-specific Balance Confidence, $\mathrm{CWS}=$ controlled walking speed, DLW $=$ doubly labeled water, $\mathrm{EBP}=$ evidence-based practice, $\mathrm{EES}=$ empirical evidence statement, $\mathrm{EV}=$ external validity, $\mathrm{GRF}=$ ground reaction force, $\mathrm{HAI}=$ Hill Assessment Index, HRQL = health-related quality of life, IV $=$ internal validity, $\mathrm{LLL}=$ lower-limb loss, MFCL $=$ Medicare Functional Classification Level, MP = microprocessor, MPC = microprocessor control, MPK = microprocessor-controlled prosthetic knee, MRPP = Montreal Rehabilitation Performance Profile, NMPK = non-microprocessor-controlled prosthetic knee, $\mathrm{O}_{2}=$ oxygen, $\mathrm{O} \& \mathrm{P}=$ orthotic and prosthetic, $\mathrm{PAEE}=$ physical activity-related energy expenditure, PCBS $=$ Prosthetic Cognitive Burden Scale, PCI = physiological cost index, PEQ = Prosthesis Evaluation Questionnaire, PEQ-A = PEQ Addendum, $\mathrm{PRO}=$ patient-reported outcome, $\mathrm{QALY}=$ quality adjusted life year, $\mathrm{QOL}=$ quality of life, $\mathrm{RPE}=$ rating of perceived exertion, SAI $=$ Stair Assessment Index, SF-36 = 36-Item Short-Form Health Survey, SOT $=$ sensory organization test, SSWS $=$ selfselected walking speed, $\mathrm{SSC}=$ State of the Science Conference, $\mathrm{TDEE}=$ total daily energy expenditure, TFLL $=$ transfemoral limb loss.

*Address all correspondence to Andrew B. Sawers, CPO, PhD; The Wallace H. Coulter Department of Biomedical Engineering, Emory University and the Georgia Institute of Technology, 313 Ferst Dr, Atlanta, GA 30332.

Email: andrew.b.sawers@emory.edu

http://dx.doi.org/10.1682/JRRD.2011.10.0187 


\section{INTRODUCTION}

The loss or absence of a limb is a serious bodily impairment caused by disease, trauma, or congenital disorder. Current estimates indicate that upper- and lowerlimb loss (LLL) affects more than 1.6 million individuals living in the United States [1]. The rising incidence of dysvascular amputation, most recently reported in the period between 1988 and 1996 [2], has contributed to an overall 19 percent increase in persons with limb loss between 1996 and 2005 [1,3]. Moreover, the aging population and growing incidence of health conditions such as obesity, diabetes, and dysvascular disease are predicted to elevate the prevalence of limb loss in the United States to more than 3.6 million individuals by the year 2050 [1]. This trend insinuates not only a need to improve preventative care, research, and education related to limb loss but also the means to provide appropriate assistive technology to a growing population of individuals facing acute physical challenges.

The most severe form of physical impairment associated with limb loss or absence traditionally involves major (i.e., nondigit) loss of the limb. More than 42 percent of all amputations are attributed to major limb loss, with the vast majority (approximately 94\%) [1] occurring in the lower limb. Given the importance of the lower limb to balance, transfer, and ambulation activities, LLL negatively affects an individual's functional ability at home and in the community [4-9]. For example, a 2006 systematic review of walking ability following LLL noted that, while 56 to 97 percent of individuals regain walking ability following LLL, only 26 to 62 percent regain the ability to ambulate outdoors [4]. This specific limitation seems critical because an inability to ambulate outside of the home may impede participation in both vocational and avocational activities and increase reliance on physical, personal, and financial assistance.

The physiological and functional challenges associated with LLL are also exacerbated at more proximal levels of LLL [8,10-13], as evidenced by significantly fewer individuals with transfemoral limb loss (TFLL) than individuals with transtibial limb loss who are reported to achieve household $(50 \%$ vs $66 \%)$ or community ( $29 \%$ vs 54\%) ambulation [8]. TFLL, when compared with LLL at more distal levels, has also been reported to be associated with a decreased frequency of prosthetic fitting $[7,14-15]$ and an increased frequency of back, knee, and hip pain [16-19]; obesity [20]; and osteoarthritis [17,21].
These medical issues may ultimately contribute to the extended period of disability and failure to return to work that have been associated with TFLL [22].

Among the many documented functional challenges facing individuals with TFLL, those commonly cited include decreased balance [23-29]; increased metabolic energy expenditure while walking [30-34]; decreased walking speed [31,33,35-36]; gait asymmetries [35-38]; increased frequency of stumbles and falls [27,39]; reduced activity level [40-42]; difficulty negotiating uneven terrain, hills, and stairs [23,43-45]; and increased cognitive demand while walking [46-47]. LLL may also affect patients' health-related quality of life (HRQL), as suggested by lower 36-Item Short-Form Health Survey (SF36) scores [48-51] among individuals with TFLL than nondisabled individuals [52-53]. Correspondingly, surgical, medical, therapeutic, and prosthetic interventions that address these challenges are considered important to the successful rehabilitation of individuals with TFLL.

A wide variety of prosthetic interventions are available to address functional limitations that result from LLL [54-58]. For individuals with TFLL, selecting an appropriate prosthetic knee is considered to be a critical element in the successful outcome of a patient [59]. A prosthetic knee is typically chosen to provide both the stability and agility users require for balancing and ambulating effectively. Although more than 220 different prosthetic knee products are available to address the breadth of individual user needs [60], no universal system for classification exists to describe the function, features, or benefits of individual prosthetic knees. Clinical conventions in use today often categorize prosthetic knees according to the hinge type and control system inherent in the unit $[59,61]$. Additionally, a prosthetic knee's stability behavior (i.e., stance control) is commonly described independently from those features that provide agility (i.e., swing control) to provide a complete overview of the prosthetic knee's function.

Traditional prosthetic knees are available in either single-axis or polycentric designs. Stance stability for these is determined by the position of knee joint (singleaxis hinge) or instant center of rotation (polycentric hinge) with respect to the ground reaction force (GRF) vector and is commonly augmented by inherent features such as a mechanical lock, mechanical friction brake, and/ or hydraulic resistance mechanism. The prosthetic knee's agility in swing may similarly be supplemented with intrinsic features such as a mechanical friction brake, 
elastic extension assist, and/or fluid (i.e., hydraulic or pneumatic) that act to regulate resistance of the knee joint, thereby contributing to a user's ability to vary his or her cadence and walking speed. The behavior is then set by a prosthetist through mechanical adjustments to the alignment and/or the intrinsic stance and swing features of the prosthetic knee. Once these parameters have been fixed, the prosthetic knee will perform consistently in response to the loading conditions with which it is presented.

Contemporary prosthetic knees also include models that incorporate a microprocessor (MP) within the unit [62]. These MP-controlled prosthetic knees (MPKs), while similar in basic function (i.e., stability in stance, agility in swing) to non-MP-controlled prosthetic knees (NMPKs), allow the MP to perpetually "fine-tune" many of the prosthetic knee's intrinsic behaviors. This allows an MPK to resist or allow flexion in response to load, position, and/or velocity sensors. This technology is intended to make the prosthetic knee responsive to the user's instantaneous needs (i.e., allow him or her to change cadence and walking speed) and adjust its behavior (i.e., provide more or less knee-flexion resistance) in response to extrinsic conditions, thereby mimicking the behavior of a nondisabled knee.

Note that there are a variety of MPKs available and that the control afforded to the MP differs among prosthetic knees. For example, some MPKs regulate only the stance behavior (e.g., Compact C-Leg, Otto Bock; Minneapolis, Minnesota) and some regulate only the swing behavior (e.g., SmartIP, Endolite; Miamisburg, Ohio), while others regulate both the stance and swing behavior (e.g., Compact C-Leg and RHEO KNEE; Össur Americas; Foothill Ranch, California). In general, the more control afforded to the MP, the greater the sophistication and cost of the device. However, inclusion of an MP into the prosthetic knee is believed to provide a number of theoretical benefits to the user, including improvements in balance, confidence, uneven terrain ambulation, stair descent, incline negotiation, and overall activity, as well as a reduction in adverse events such as stumbles and falls.

Although MPKs have been clinically available and actively prescribed for individuals with TFLL for more than $15 \mathrm{yr}$ [63], the body of research related to these devices is relatively small and diverse. The number of published, peer-reviewed research studies in this area has grown in recent years, but widespread translation of this knowledge for clinical and scientific purposes has yet to occur. Thus, it seems an opportune time to systematically review, critically evaluate, and appropriately synthesize the body of knowledge in order to address this need. At the time of this review (October 2009), no such endeavor had been undertaken. Specifically, no comprehensive, peer-reviewed systematic evaluation of the effectiveness of MPKs in the rehabilitation of individuals with TFLL had been identified. Such information would be immediately useful to inform clinical practice, advise reimbursement decisions, and direct future research.

The purpose of this systematic review was therefore to evaluate the state of the science in MPK research and to synthesize this knowledge for dissemination. Such information could then be used to form evidence-based practice (EBP) clinical guidelines regarding the safe and effective implementation of this rapidly evolving technology and to develop future research questions. We carefully constructed a specific question to address these aims and to direct this systematic review. We developed the question using the PICO (Patient/Population Intervention Comparison Outcome) method [64], a recognized technique for developing a well-built and clinically relevant question [64-66]. We also phrased the question in a neutral manner to avoid bias toward the efficacy of the intervention and allow for an objective assessment of the scientific literature. For the purposes of this review, we elected to answer the question, Does the prescription, fit, and use of MPKs lead to changes in outcomes for individuals with unilateral TFLL when compared with NMPKs?

\section{METHODS}

\section{Literature Search}

We conducted a systematic search of the literature in October 2009 using several healthcare and biomedicine databases, including PUBMED (1949 to October 2009), CINHAL (1981 to October 2009), RECAL Legacy (early 1900s to October 2009), and the Cochrane Library (1996 to October 2009). We searched the databases using generic key words related to MPKs and augmented with specific terms related to two specific prosthetic knee products, the Compact C-Leg and SmartIP, that we knew to be the focus of multiple, independent scientific research studies. We combined the key words into a single search phrase using Boolean operators to standardize the search across the databases. The syntax used in the PUBMED, CINAHL, and Cochrane Library databases was as follows: ((microprocessor AND knee AND prosth*) OR (C-Leg) OR (intelligent 
AND prosth*)). We amended the search of the RECAL Legacy database by removing the search term "C-Leg" because its use was interpreted by the database as the term "leg," thus resulting in an excessive number of unrelated results. We also identified additional manuscripts by searching references of initially included publications.

\section{Inclusion and Exclusion Criteria}

We established specific a priori inclusion and exclusion criteria in order to select those publications that met specific criteria, were written in or translated into English, and were relevant to the stated purpose of the review. We restricted publications to those published in peer-reviewed journals. We did not include conference proceedings, white papers, theses, or dissertations. We did not limit publications by study design or methodological quality, and we considered all structured reviews, experimental trials, and observational studies [67] for inclusion to adequately consider the overall state of the science in this area.

We similarly developed inclusion and exclusion criteria pertaining to study interventions and populations to select those most suited to answering the guiding question of this review. We included studies that compared any type of MPK (i.e., swing-phase MP control [MPC], stance-phase MPC, or swing and stance MPC) with any type of NMPK. Similarly, we considered studies that included subjects with TFLL or knee disarticulation LLL because both MPKs and NMPKs are prescribed and fit to these subjects and sagittal-plane control of a prosthetic knee at either level is based on similar biomechanical principles. Conversely, we excluded studies that included individuals with bilateral LLL to avoid confounding factors related to bilateral involvement. Although MPKs are prescribed for individuals with bilateral LLL, biomechanical performance and function of individuals with bilateral LLL differs greatly from those with unilateral LLL [33,68-69]. Similarly, we excluded studies of subjects who required walking aids, such as crutches, canes, or walkers, to avoid potentially confounding factors related to ambulation with an assistive device [33,70]. We applied no exclusion criteria based on the LLL etiology of study subjects. Lastly, we included studies with individuals aged $\geq 16 \mathrm{yr}$ because this is the population for whom MPKs are currently designed.

\section{Assessment of Methodological Quality}

We independently appraised the study design and methodological quality of those publications that met the inclusion and exclusion criteria according to guidelines developed by the American Academy of Orthotists and Prosthetists (AAOP) [71]. When we could not obtain consensus regarding either methodological quality or study design, we discussed the relevant issues until we achieved consensus. In situations where there existed a perceived conflict of interest, an alternate qualified reviewer participated in the assessment of the study methodological quality. This situation occurred in two instances when one of the authors (B.H.) was a contributing author to the reviewed publications [72-73].

We classified study design according to the AAOP Study Design Classification Scale, a 15-level categorization scheme based on the type of described study [71]. In situations where a single publication described multiple types of study designs, we assigned the overall classification according to the predominant study design. We rated study methodological quality using the State of the Science Conference (SSC) Quality Assessment Form, two checklists developed to facilitate standardized assessment of internal validity (IV) and external validity (EV) across multiple studies [71]. The SSC Quality Assessment Form identifies up to 18 potential threats to IV and 8 potential threats to EV that may be relevant to the study designs noted in the AAOP Study Design Classification Scale. We independently evaluated each criterion on the SSC Quality Assessment Form, which were deemed to be "met" (noted with a "•" in Table 1) if the publication addressed the specified threat. Appendixes 1 and 2 (available online only) provide a description of the information that was required to be presented in the publication in order to meet each criterion. Note that we deemed a number of methodological criteria to be "not applicable" to selected study designs [71]. For example, IV criteria 1 to 4 and 12 pertain only to experimental group study designs (i.e., randomized controlled trial $\left[\mathrm{E}_{1}\right]$ or controlled trial $\left.\left[E_{2}\right]\right)$. Appendixes 1 and 2 show details regarding those IV and EV criteria we deemed to be applicable to each type study design.

We then rated the IV and EV of each publication as "high," "moderate," or "low." We generally rated publications high for IV or EV if none or one of the criterion were not met and any that were not met posed minimal risks to validity (e.g., criterion EV-5: "intervention adequately described"). We rated publications as moderate for IV or 
Table 1.

Internal validity (IV) and external validity (EV) of included studies.

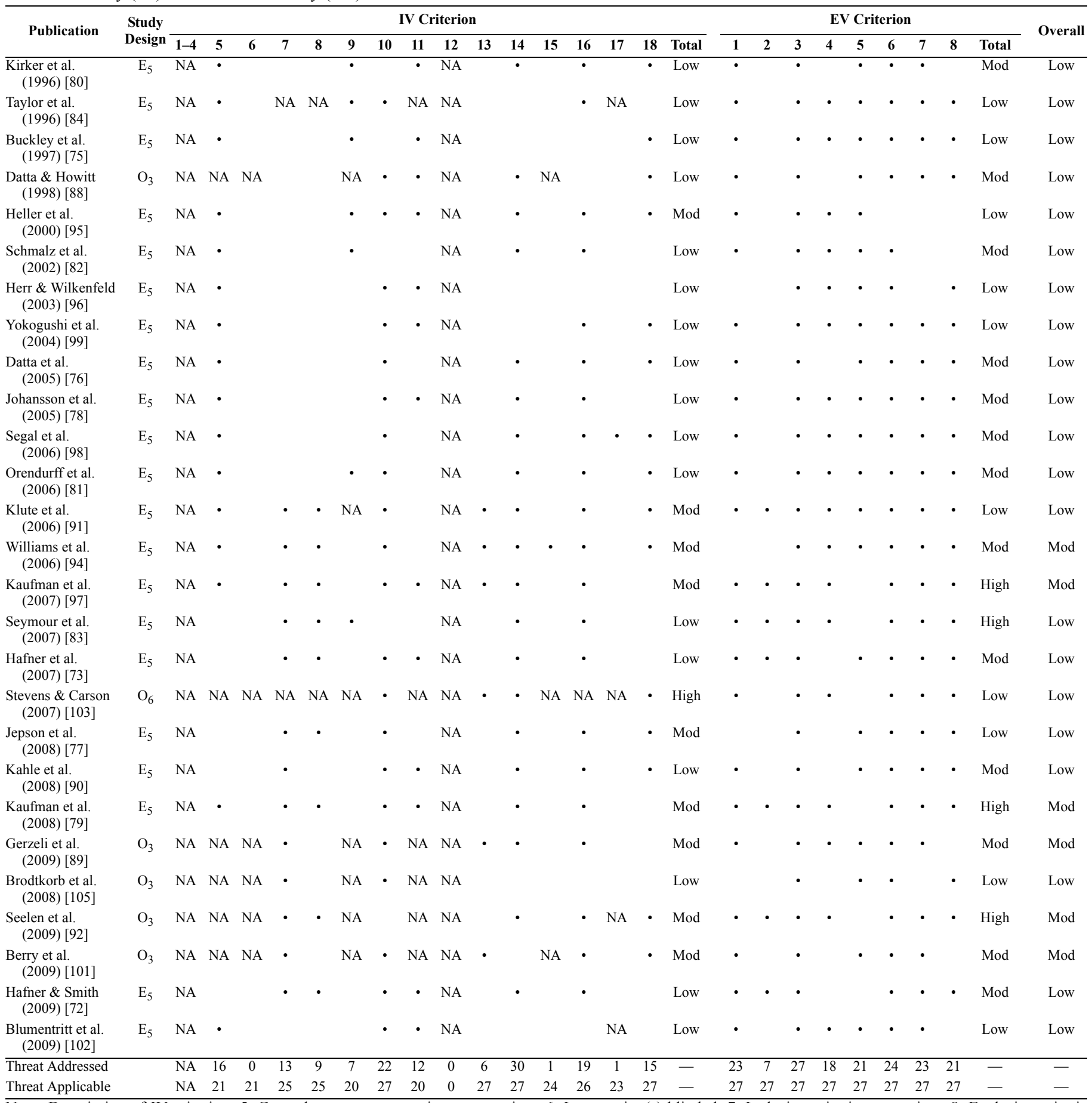

Note: Description of IV criterion: 5. Control group or comparison appropriate; 6. Intervention(s) blinded; 7. Inclusion criteria appropriate; 8 . Exclusion criteria appropriate; 9. Protocol addresses fatigue and learning; 10. Protocol addresses accommodation and washout; 11. Attrition explained and less than 20\%; 12 . Attrition equal between groups; 13. Outcome measures reliable; 14. Statistical analysis appropriate; 15. Effect size reported; 16. Statistical significance reported; 17. Statistical power adequate; 18 . Free from conflicts of interest. Description of EV criterion: 1. Sample characteristics adequately described; 2 . Sample representative of target population; 3 . Outcome measures adequately described; 4 . Outcome measures valid for this study; 5 . Intervention adequately described; 6 . Findings clinically significant/relevant; 7. Conclusions placed in context of existing literature; 8. Conclusions supported by findings.

$\mathrm{E}_{5}=$ controlled before-and-after trial, Mod $=$ moderate, $\mathrm{NA}=$ particular threat to IV or EV not applicable to particular study design, $\mathrm{O}_{3}=$ cross-sectional study, $\mathrm{O}_{6}=$ case study, $\bullet=$ threat to IV or EV was adequately described in publication, blank = threat to IV or EV was not adequately described in publication. 
$\mathrm{EV}$ if more than one but less than half of the applicable criteria were not met. We rated publications as low when half or more of the applicable criteria were not met. We instituted two exceptions to these rules. First, we deemed publications ineligible for a high EV rating if the study sample included 10 or fewer participants. Second, we deemed publications ineligible for a moderate $\mathrm{EV}$ rating if the study sample included five or fewer participants. We instituted these exceptions to reflect the inherent difficulties in generalizing results from small samples to a larger population even when other threats to EV are addressed. Although this objective method for assigning ratings of methodological quality differs slightly from recommendations described in the AAOP Study Design Classification Scale [71], we considered this to be a fair and reasonable approach to evaluating a publication's contributions to the overall evidence. Sanders and Fatone recently described a similar approach to application of the AAOP Study Design Classification Scale methodological criterion [74].

Lastly, we assigned publications a "high," "moderate," or "low" overall methodological quality rating. We defined overall ratings according to the lower of the IV and EV ratings to reflect a conservative estimate of the evidence provided by the publication. We used a publication's overall rating to justify the level of evidence that exists to support developed empirical evidence statements (EESs).

\section{Empirical Evidence Statements}

We used results obtained from individual publications that compared MPKs with NMPKs to develop the EESs. We grouped them into nine outcome topics: (1) metabolic energy expenditure, (2) activity, (3) cognitive demand, (4) gait mechanics, (5) environmental obstacle negotiation, (6) safety, (7) preference and satisfaction, (8) economics, and (9) health and quality of life (QOL). For each topic, we developed specific EESs to summarize the statistically significant findings reported in the reviewed literature. We based EESs on the findings from the research and the type of MPK (i.e., swing-phase MPC, stance-phase MPC, or swing and stance MPC) to which those results applied. We developed EESs when two or more studies reported results pertaining to a single outcome. We did not include additional demographic descriptors such as etiology, age, or activity level within the EESs because of inconsistent reporting of such variables across the reviewed body of literature. We determined the directionality (i.e., increased, decreased, or equivalent) of each EES by those studies that reported statistically significant findings related to the developed EES. We then substantiated each EES by examining (1) the number of publications contributing to the EES, (2) the overall methodological quality of those studies, and (3) whether the contributing findings were confirmatory or conflicting. Based on these three criteria, we qualified each EES with a level of evidence. We defined the levels of evidence a priori as "high," "moderate," "low," or "insufficient" according to the definitions in Table 2. Note that, in situations where we believed multiple publications described the same study (i.e., same investigators, same group of subjects) and contributed to the same EES, the results of both publications did not strengthen the level of evidence.

\section{RESULTS}

\section{Literature Search}

The described search strategy yielded 241 unique citations across the four chosen databases. Of these, we

Table 2.

Definitions of level of evidence supporting empirical evidence statements.

\begin{tabular}{|c|c|}
\hline $\begin{array}{l}\text { Evidence } \\
\text { Level }\end{array}$ & Definition \\
\hline High & $\begin{array}{l}\text { Reviewers found high level of evidence to support statement based on findings from multiple independent peer- } \\
\text { reviewed studies of moderate to high overall methodological quality that demonstrate consistent results in support } \\
\text { of statement. }\end{array}$ \\
\hline Medium & $\begin{array}{l}\text { Reviewers found moderate level of evidence to support statement based on findings from multiple independent } \\
\text { peer-reviewed studies of low to moderate overall methodological quality that demonstrate consistent results in } \\
\text { support of statement. }\end{array}$ \\
\hline Low & $\begin{array}{l}\text { Reviewers found low level of evidence to support statement based on findings from multiple peer-reviewed studies } \\
\text { of low methodological quality or presence of substantial findings that are inconsistent with statement. }\end{array}$ \\
\hline Insufficient & Reviewers found insufficient evidence to support statement due to multiple studies with conflicting results. \\
\hline
\end{tabular}


initially selected 69 based on a review of their titles. We added two additional publications from searching the references in these initial 69 publications. Upon review of the abstracts (and full-length manuscripts, as necessary), 27 of the 71 publications met the a priori inclusion and exclusion criteria established for this review. The included publications spanned the years 1996 to 2009. Of the 27 included publications, nearly two-thirds were published after 2005. The publications selected for review were predominantly sourced from rehabilitation or orthotic and prosthetic (O\&P) peer-reviewed journals. Several were published in journals that focused on engineering, economics, and human movement.

\section{Study Demographics}

We classified the reviewed studies into 5 of the 15 potential designs described by the AAOP Study Design Classification Scale [71], including controlled beforeand-after trials, case-controlled studies, cross-sectional studies, case series, and case studies. Sample sizes ranged from 1 to $368($ mean $=27$, median $=8)$. The cause of LLL in study subjects was predominantly (i.e., approximately 90 percent of all subjects) nondysvascular (i.e., trauma, tumor, osteomyelitis, congenital, or other). The description of study subjects' activity level or ability to ambulate was often vague in studies published prior to 2005. However, we believed subjects across this body of literature to be at the level of a community ambulator (i.e., Medicare Functional Classification Level [MFCL]2) or higher based on the descriptions provided.

All of the studies published prior to 2001 included swing phase-only MPKs as the intervention of interest; the vast majority of manuscripts (20 of 22) published after 2001 focused on swing and stance MPKs. In total, 20 of the 27 reviewed publications described comparisons between swing and stance MPKs and NMPKs, while the remaining 7 described comparisons between swing phaseonly MPKs and NMPKs. No study that met the described selection criteria included both types of MPKs. Outcomes reported in the reviewed publications included metabolic energy expenditure, activity, cognitive demand, gait mechanics, negotiation of environmental obstacles, safety, preference and satisfaction, economics, and health and QOL. Most publications described more than one outcome.

\section{Methodological Quality Assessment}

Assessment of overall methodological quality, based on the aforementioned approach, identified 21 publica- tions of low and 6 of overall moderate methodological quality. The publications' IV scores, rather than their EV scores, were often the reason why overall methodological quality was reduced (Table 1). Among the 17 publications that we determined to have moderate or high EV, we assigned 11 low overall methodological quality as a result of low IV. Conversely, of the 10 publications that we noted to have moderate or high IV, we assigned 4 low overall methodological quality because of low EV.

\section{Empirical Evidence Statements}

Based on the findings reported in the 27 reviewed studies, we created and organized 28 EESs into 9 outcome topics. We wrote the EESs to indicate the extent to which the empirical evidence suggests that the prescription and use of MPKs results in changes to rehabilitationrelated outcome measures among individuals with unilateral TFLL when compared with the use of NMPKs. Each of the EESs is accompanied by a level of evidence that indicates the degree to which the accumulated evidence supports it. Note that we generalized EESs developed for this review to the population of individuals with unilateral TFLL. Refer to Table 3 for additional study and subject demographics that may inform the generalizability of the EES to specific individuals.

\section{Metabolic Energy Expenditure}

Metabolic energy expenditure outcomes are those associated with measures of the physiological energy requirements of ambulation. Measures of energy expenditure reported in the MPK literature include oxygen $\left(\mathrm{O}_{2}\right)$ cost, $\mathrm{O}_{2}$ rate, total daily energy expenditure (TDEE), physical activity-related energy expenditure (PAEE), physiological cost index (PCI), and rating of perceived exertion (RPE) [75-84].

$\mathrm{O}_{2}$ cost, the $\mathrm{O}_{2}$ consumed (normalized to body weight) per unit distance traveled during ambulation has been reported in the literature for comparisons between NMPKs and both swing and stance $[79,81,83]$ and swing-only MPKs [75-76]. $\mathrm{O}_{2}$ cost was measured primarily while subjects walked at a self-selected walking speed (SSWS) and/or at a controlled walking speed (CWS) on a treadmill $[75-76,79,83]$. However, one study measured this outcome as subjects walked over level ground in a laboratory [81]. Comparisons between swing and stance MPKs and NMPKs showed mixed results. In two studies, NMPK users were transitioned to the swing and stance MPK in either a sequential or randomized 
JRRD, Volume 50, Number 3, 2013

Table 3.

Characteristics of included studies.

\begin{tabular}{|c|c|c|c|c|c|c|c|c|c|}
\hline Publication & $\begin{array}{l}\text { Study } \\
\text { Design }\end{array}$ & $\begin{array}{l}\text { Intervention } \\
\text { (MPK) }\end{array}$ & $\begin{array}{l}\text { Comparison } \\
\text { (NMPK) }\end{array}$ & $\begin{array}{l}\text { Sample } \\
\text { Size (n) }\end{array}$ & Age (yr) ${ }^{*}$ & Etiology (n) & $\begin{array}{c}\text { Activity or } \\
\text { Functional Level }\end{array}$ & $\begin{array}{c}\text { Time Since } \\
\text { Limb Loss (yr) }\end{array}$ & $\begin{array}{c}\text { Outcome } \\
\text { Topic }\end{array}$ \\
\hline $\begin{array}{l}\text { Kirker et al. } \\
\text { (1996) [80] }\end{array}$ & $\mathrm{E}_{5}$ & $\begin{array}{l}\text { Weight-activated locking } \\
\text { (ST); MP fluid (SW) }\end{array}$ & $\begin{array}{r}\text { Weight-activated locking } \\
\text { (ST); Pneumatic (SW) }\end{array}$ & 6 & $36.5(29-44)$ & $\begin{array}{l}\text { Traumatic (ND); } \\
\text { Congenital (ND) }\end{array}$ & $\begin{array}{l}\text { Regularly walk at } \\
\text { different speeds }\end{array}$ & $16.5(7-44)$ & $1,4,7$ \\
\hline $\begin{array}{l}\text { Taylor et al. } \\
\text { (1996) [84] }\end{array}$ & $\mathrm{E}_{5}$ & $\begin{array}{l}\text { Weight-activated locking } \\
\text { (ST); MP fluid (SW) }\end{array}$ & Various & 1 & 33.0 & Traumatic (1) & Active & NR & 1 \\
\hline $\begin{array}{r}\text { Buckley et al. } \\
\text { (1997) [75] }\end{array}$ & $\mathrm{E}_{5}$ & $\begin{array}{l}\text { Weight-activated locking } \\
\text { (ST); MP fluid (SW) }\end{array}$ & $\begin{array}{l}\text { Weight-activated locking } \\
\text { (ST); Pneumatic (SW) }\end{array}$ & 3 & NR (39-59) & Traumatic (3) & Fit/active & NR & 1 \\
\hline $\begin{array}{l}\text { Datta \& Howitt } \\
\text { (1998) [88] }\end{array}$ & $0_{3}$ & $\begin{array}{l}\text { Weight-activated locking } \\
\text { (ST); MP fluid (SW) }\end{array}$ & $\begin{array}{r}\text { Weight-activated locking } \\
\text { (ST); Pneumatic (SW) }\end{array}$ & 22 & $39.9(25-76)$ & $\begin{array}{l}\text { Traumatic (16); Tumor (5); } \\
\text { Osteomyelitis (1) }\end{array}$ & Fairly active & $19.2(5-53)$ & 2,7 \\
\hline $\begin{array}{l}\text { Heller et al. } \\
\qquad(2000)[95]\end{array}$ & $\mathrm{E}_{5}$ & $\begin{array}{l}\text { Weight-activated locking } \\
\text { (ST); MP fluid (SW) }\end{array}$ & $\begin{array}{r}\text { Weight-activated locking } \\
\text { (ST); Pneumatic (SW) }\end{array}$ & 10 & $38.0(23-46)$ & $\begin{array}{l}\text { Traumatic (8); } \\
\text { Tumor (2) }\end{array}$ & NR & $>5(\mathrm{NR})$ & 3 \\
\hline $\begin{array}{r}\text { Schmalz et al. } \\
(2002)[82]\end{array}$ & $E_{5}$ & $\begin{array}{l}\text { MP fluid (ST); MP fluid } \\
\text { (SW) }\end{array}$ & $\begin{array}{l}\text { Hydraulic (ST); Hydraulic } \\
\text { (SW) }\end{array}$ & 6 & $37.0(27-53)$ & Traumatic (6) & NR & $13.0(1-29)$ & 1 \\
\hline $\begin{array}{l}\text { Herr \& Wilken- } \\
\text { feld (2003) [96] }\end{array}$ & $E_{5}$ & $\begin{array}{l}\text { MP fluid (ST); MP fluid } \\
\text { (SW) }\end{array}$ & Various & 4 & $39.0(25-48)$ & NR (4) & NR & $>2(\mathrm{NR})$ & 4 \\
\hline $\begin{array}{l}\text { Yokogushi et al. } \\
\text { (2004) [99] }\end{array}$ & $\mathrm{E}_{5}$ & Fluid (ST); MP fluid (SW) & $\begin{array}{l}\text { Position locking (ST); } \\
\text { Hydraulic (SW) }\end{array}$ & 3 & 28.0 (NR) & Traumatic (3) & NR & $>3$ (NR) & 4 \\
\hline $\begin{array}{l}\text { Datta et al. } \\
\text { (2005) [76] }\end{array}$ & $\mathrm{E}_{5}$ & $\begin{array}{l}\text { Weight-activated locking } \\
\text { (ST); MP fluid (SW) }\end{array}$ & $\begin{array}{l}\text { Weight-activated locking } \\
\text { (ST); Pneumatic (SW) }\end{array}$ & 10 & $38.0(23-46)$ & $\begin{array}{l}\text { Traumatic (8); } \\
\text { Tumor (2) }\end{array}$ & NR & $>5$ (NR) & 4 \\
\hline $\begin{array}{l}\text { Johansson et al. } \\
\text { (2005) [78] }\end{array}$ & $\mathrm{E}_{5}$ & $\begin{array}{l}\text { MP fluid (ST); MP fluid } \\
\text { (SW) }\end{array}$ & $\begin{array}{l}\text { Hydraulic (ST); Hydraulic } \\
\text { (SW) }\end{array}$ & 8 & NR (29-54) & $\begin{array}{l}\text { Traumatic (3); Tumor (2); } \\
\text { Infection (2); } \\
\text { Congenital (1) }\end{array}$ & $\mathrm{MFCL} \geq \mathrm{K} 3$ & NR & 1,4 \\
\hline $\begin{array}{l}\text { Segal et al. } \\
\text { (2006) [98] }\end{array}$ & $\mathrm{E}_{5}$ & $\begin{array}{l}\text { MP fluid (ST); MP fluid } \\
\text { (SW) }\end{array}$ & $\begin{array}{l}\text { Hydraulic (ST); Hydraulic } \\
\text { (SW) }\end{array}$ & 8 & $47.0(28-60)$ & Traumatic (8) & NR & $>3$ (NR) & 4 \\
\hline $\begin{array}{l}\text { Orendurff et al. } \\
\text { (2006) [81] }\end{array}$ & $\mathrm{E}_{5}$ & $\begin{array}{l}\text { MP fluid (ST); MP fluid } \\
\text { (SW) }\end{array}$ & $\begin{array}{l}\text { Hydraulic (ST); Hydraulic } \\
\quad \text { (SW) }\end{array}$ & 8 & $48.5(29-61)$ & Traumatic (8) & NR & $>3$ (NR) & $1,4,7$ \\
\hline $\begin{array}{l}\text { Klute et al. } \\
\text { (2006) [91] }\end{array}$ & $\mathrm{E}_{5}$ & $\begin{array}{l}\text { MP fluid (ST); MP fluid } \\
\text { (SW) }\end{array}$ & $\begin{array}{l}\text { Hydraulic (ST); Hydraulic } \\
\text { (SW) }\end{array}$ & 5 & 48 (NR) & $\begin{array}{l}\text { Traumatic (4); } \\
\text { Tumor (1) }\end{array}$ & $\begin{array}{l}\text { Community } \\
\text { ambulators }\end{array}$ & 21 (NR) & 2 \\
\hline $\begin{array}{l}\text { Williams et al. } \\
\text { (2006) [94] }\end{array}$ & $\mathrm{E}_{5}$ & $\begin{array}{l}\text { MP fluid (ST); MP fluid } \\
\text { (SW) }\end{array}$ & $\begin{array}{l}\text { Hydraulic (ST); Hydraulic } \\
\text { (SW) }\end{array}$ & 8 & $48.5(29-61)$ & $\mathrm{NR}(8)$ & NR & NR & 3 \\
\hline $\begin{array}{l}\text { Kaufman et al. } \\
\text { (2007) [97] }\end{array}$ & $\mathrm{E}_{5}$ & $\begin{array}{l}\text { MP fluid (ST); MP fluid } \\
\text { (SW) }\end{array}$ & $\begin{array}{l}\text { Hydraulic (ST); Hydraulic } \\
\text { (SW) }\end{array}$ & 15 & $42.0(26-57)$ & $\begin{array}{l}\text { Traumatic (7); Tumor (6); } \\
\text { PVD (1); Congenital (1) }\end{array}$ & MFCL K4 & $20.0(3-36)$ & 4 \\
\hline $\begin{array}{l}\text { Seymour et al. } \\
\text { (2007) [83] }\end{array}$ & $\mathrm{E}_{5}$ & $\begin{array}{l}\text { MP fluid (ST); MP fluid } \\
\text { (SW) }\end{array}$ & Various & 13 & $46(30-75)$ & Nonvascular (13) & MFCL K4 & NR & 1,5 \\
\hline $\begin{array}{l}\text { Hafner et al. } \\
\text { (2007) [73] }\end{array}$ & $\mathrm{E}_{5}$ & $\begin{array}{l}\text { MP fluid (ST); MP fluid } \\
\quad \text { (SW) }\end{array}$ & Various & 17 & $48(21-77)$ & $\begin{array}{l}\text { Traumatic (10); Tumor (3); } \\
\text { Infection (2); PVD (1); } \\
\text { Deformity (1) }\end{array}$ & MFCL K2-K3 & $17.65(2-67)$ & $2-8$ \\
\hline $\begin{array}{l}\text { Stevens \& Carson } \\
\text { (2007) [103] }\end{array}$ & $\mathrm{O}_{6}$ & $\begin{array}{l}\text { MP fluid (ST); MP fluid } \\
\quad \text { (SW) }\end{array}$ & $\begin{array}{l}\text { Hydraulic (ST); Hydraulic } \\
\text { (SW) }\end{array}$ & 1 & 30.0 & Traumatic (1) & $\begin{array}{l}\text { Participated in running } \\
\text { and cycling }\end{array}$ & $3 \mathrm{mo}(\mathrm{NR})$ & 6 \\
\hline $\begin{array}{l}\text { Jepson et al. } \\
\text { (2008) [77] }\end{array}$ & $\mathrm{E}_{5}$ & $\begin{array}{l}\text { MP fluid (ST); MP fluid } \\
\text { (SW) }\end{array}$ & $\begin{array}{l}\text { Hydraulic (ST); Hydraulic } \\
\text { (SW) }\end{array}$ & 5 & $41.2(28.8-55.7)$ & NR (5) & NR & NR & $4,6-7$ \\
\hline $\begin{array}{l}\text { Kahle et al. } \\
\qquad(2008)[90]\end{array}$ & $\mathrm{E}_{5}$ & $\begin{array}{l}\text { MP fluid (ST); MP fluid } \\
\text { (SW) }\end{array}$ & Various & 19 & $51.0(22-83)$ & $\begin{array}{l}\text { Traumatic (7); PVD (3); } \\
\text { Diabetes (4); Congenital } \\
\text { (4); Tumor (1) }\end{array}$ & $\mathrm{MFCL} \geq \mathrm{K} 2$ & NR (3-36) & $2,4-7$ \\
\hline $\begin{array}{l}\text { Kaufman et al. } \\
\text { (2008) [79] }\end{array}$ & $\mathrm{E}_{5}$ & $\begin{array}{l}\text { MP fluid (ST); MP fluid } \\
\text { (SW) }\end{array}$ & Various & 15 & $42.0(26-57)$ & $\begin{array}{l}\text { Traumatic (7); Tumor (6); } \\
\text { PVD (1); Congenital (1) }\end{array}$ & MFCL K4 & $200.0(3-36)$ & $1-2,8$ \\
\hline $\begin{array}{l}\text { Gerzeli et al. } \\
\text { (2009) [89] }\end{array}$ & $\mathrm{O}_{3}$ & $\begin{array}{l}\text { MP fluid (ST); MP fluid } \\
\text { (SW) }\end{array}$ & NS & 100 & 45.8 (NR) & $\begin{array}{l}\text { Dysvascular (4); } \\
\text { Traumatic (96) }\end{array}$ & $\begin{array}{l}\text { Daily use (hr): MPK: } \\
\text { 13.5; NMPK: } 11.7\end{array}$ & 13.7 (NR) & 2,9 \\
\hline $\begin{array}{l}\text { Brodtkorb et al. } \\
\quad(2008)[105]\end{array}$ & $\mathrm{O}_{3}$ & $\begin{array}{l}\text { MP fluid (ST); MP fluid } \\
\text { (SW) }\end{array}$ & NS & 20 & $41.0(\mathrm{NR})$ & NR & NR & $16.0(\mathrm{NR})$ & 9 \\
\hline $\begin{array}{l}\text { Seelen et al. } \\
\quad(2009)[92]\end{array}$ & $\mathrm{O}_{3}$ & $\begin{array}{l}\text { MP fluid (ST); MP fluid } \\
\text { (SW) }\end{array}$ & Various & 26 & 47.0 (NR) & $\begin{array}{l}\text { Dysvascular (5); } \\
\text { Traumatic (16); } \\
\text { Tumor (5) }\end{array}$ & NR & $\begin{array}{l}\text { MPK: } 13.2 ; \\
\text { NMPK: } 11.4 \\
(\mathrm{NR})\end{array}$ & $2,8-9$ \\
\hline $\begin{array}{l}\text { Berry et al. } \\
\text { (2009) [101] }\end{array}$ & $\mathrm{O}_{3}$ & $\begin{array}{l}\text { MP fluid (ST); MP fluid } \\
\text { (SW) }\end{array}$ & Various & 368 & $54.7(15-85)$ & Mixed (368) & MFCL K3 & NR $(0.2-78.7)$ & 6 \\
\hline $\begin{array}{l}\text { Hafner \& Smith } \\
\text { (2009) [72] }\end{array}$ & $\mathrm{E}_{5}$ & $\begin{array}{l}\text { MP fluid (ST); MP fluid } \\
\text { (SW) }\end{array}$ & Various & 17 & $48.0(21-77)$ & $\begin{array}{l}\text { Traumatic (10); Tumor (3); } \\
\text { Infection (2); PVD (1); } \\
\text { Deformity (1) }\end{array}$ & MFCL K2-K3 & $17.65(2-67)$ & $\begin{array}{l}2-3,5- \\
6,8\end{array}$ \\
\hline $\begin{array}{l}\text { Blumentritt et al. } \\
\text { (2009) [102] }\end{array}$ & $\mathrm{E}_{5}$ & $\begin{array}{l}\text { MP fluid (ST); MP fluid } \\
\text { (SW) }\end{array}$ & Various & 3 & $\mathrm{NA}(25-43)$ & $\begin{array}{l}\text { Traumatic (2); } \\
\quad \text { Tumor (1) }\end{array}$ & MOBIS 3-4 & $19(9-26)$ & 6 \\
\hline
\end{tabular}

*Mean (range).

Note: Outcome topics: 1. metabolic energy expenditure, 2. activity, 3. cognitive demand, 4. gait mechanics, 5. environmental obstacle negotiation, 6. safety, 7. preference and satisfaction, 8. health and quality of life, 9. economics.

$\mathrm{E}_{5}=$ controlled before-and-after trial, MFCL $=$ Medicare Functional Classification Level, MOBIS $=$ Mobility System, MP $=$ microprocessor, $\mathrm{MPK}=$ microprocessorcontrolled knee, $\mathrm{NA}=$ particular threat to internal or external validity not applicable to particular study design, ND $=$ not defined, NMPK $=$ non-microprocessor-controlled knee, $\mathrm{NR}=$ not reported, $\mathrm{NS}=$ not specified, $\mathrm{O}_{3}=$ cross-sectional study, $\mathrm{O}_{6}=$ case study, $\mathrm{PVD}=$ peripheral vascular disease, $\mathrm{ST}=$ stance-control mechanism, $\mathrm{SW}=$ swing-control mechanism. 
order and no significant difference in $\mathrm{O}_{2}$ cost between interventions at either SSWS or CWS was reported $[79,81]$. Users were provided with at least $10 \mathrm{wk}$ to accommodate to the MPK in these studies. A study of active (i.e., MFCL-4) and established MPK users found that significantly increased $\mathrm{O}_{2}$ costs were incurred when users wore the NMPK prosthesis at SSWS and CWS [83]. Subjects were given $5 \mathrm{~min}$ to accommodate to the NMPK prosthesis before testing. A single study of 10 subjects reported a decrease in $\mathrm{O}_{2}$ cost when subjects wore a swing-only MPK compared with an NMPK [76]. The difference was reported as significant, but only at speeds below SSWS. No accommodation to the MPK outside of the test session was provided.

$\mathrm{O}_{2}$ rate, the $\mathrm{O}_{2}$ consumed (normalized to body weight) per unit time of steady-state physical activity, was similarly reported in a number of studies comparing NMPKs with both types of MPKs [78,80,82-84]. Three studies of between 6 and 10 subjects reported significantly reduced $\mathrm{O}_{2}$ rates at SSWS when the users wore the swing and stance MPK compared with the NMPK [78,82-83]. Two studies that reported results for fast walking speeds conflicted, because one found a significant decrease in $\mathrm{O}_{2}$ rate while using a swing and stance MPK when compared with the NMPK [83], while the other found no significant difference between the interventions [82]. Several smaller studies consisting of one to six subjects reported no significant differences in $\mathrm{O}_{2}$ rate when individuals used a swing-only MPK compared with using NMPKs [75,80,84]. All of the $\mathrm{O}_{2}$ rate studies tested both interventions on the same day $[75,80,84]$.

Kaufman et al. [79] examined metabolic energy expenditure in the free-living environment using a doubly labeled water (DLW) technique [85]. Subjects were monitored over $10 \mathrm{~d}$ periods as they used either a swing and stance MPK or a swing and stance NMPK. Kaufman et al. used the obtained data to calculate each subject's TDEE and PAEE over the observation period. They reported that subjects' overall TDEE did not significantly differ between interventions, but the metabolic energy expenditure associated with activity significantly increased while subjects wore the MPK prosthesis.

One study [77] of four subjects wearing swing and stance MPKs and NMPKs examined energy expenditure by measuring PCI [86]. Jepson et al. tested subjects in their existing NMPKs and then again after 8 wk of accommodation to the MPK. They reported that three subjects showed an increased PCI using the MPK; the other subject showed no difference between interventions [77].

Lastly, one study [79] of 15 subjects examined subject-reported energy expenditure using the Borg RPE [87]. Subjects, who were accommodated to both prostheses at the time of assessment, reported a significantly lower RPE while using a swing and stance MPK than an NMPK after walking on a treadmill [79].

Table 4 shows the EESs we developed related to metabolic energy expenditure outcomes.

\section{Activity}

Activity outcomes are those associated with mobility or physical function in the free-living environment over an extended period of time. Measures of activity reported in the MPK literature include step counts; frequency of activity bouts; activity bout duration; and a variety of patient-reported outcomes (PROs) including the Prosthesis Evaluation Questionnaire (PEQ) ambulation subscale, SF-36 physical function subscale, EuroQol physical mobility subscale, and subject-reported walking ability [72-73,79, 88-92].

Table 4.

Metabolic energy expenditure empirical evidence statements (EESs).

\begin{tabular}{lcc}
\hline \multicolumn{1}{c}{ EES } & Supporting Study & Level of Evidence \\
\hline 1-A. Use of swing and stance MPKs results in equivalent $\mathrm{O}_{2}$ cost (at self- & $1 \times$ Moderate [79] \\
selected, slow, and fast speeds) compared with use of NMPKs among & $2 \times$ Low [81,83] \\
individuals with unilateral TFLL. & $3 \times$ Low [78,82-83] \\
1-B. Use of swing and stance MPKs results in decreased $\mathrm{O}_{2}$ rate (at self- \\
$\quad \begin{array}{l}\text { selected walking speed) compared with use of NMPKs among individuals } \\
\text { with unilateral TFLL. }\end{array}$ \\
$\begin{array}{l}\text { 1-C. Use of swing-only MPKs results in equivalent } \mathrm{O}_{2} \text { rate (at self-selected, } \\
\text { slow, and fast speeds) compared with use of NMPKs among individuals } \\
\text { with unilateral TFLL. }\end{array}$
\end{tabular}

$\overline{\mathrm{MPK}}=$ microprocessor-controlled prosthetic knee, NMPK $=$ non-microprocessor-controlled prosthetic knee, $\mathrm{O}_{2}=$ oxygen, TFLL $=$ transfemoral limb loss. 
Two studies assessed temporal measures of physical activity outside of the laboratory environment (i.e., step counts, activity bout frequency, and/or activity bout duration) [73,91] using a step activity monitor [93]. Both studies compared a swing and stance MPK with an NMPK as study subjects used the prosthetic knees in a free-living environment. The period of activity assessment ranged from 1 [91] to 2 [73] wk, and the prosthetic knees were provided to study subjects in either a sequential [73] or randomized order [91]. In both cases, the publication reported no significant differences in step-related activity outcomes between the interventions [73,91].

In contrast to objective measures of activity, subjects' self-reported activity was found to differ when using an MPK compared with an NMPK. Several investigators reported a significant increase in the PEQ Addendum (PEQ-A) for subjects using a swing and stance MPK compared with the NMPK $[72,79,90]$. Similarly, selfreported physical function, as measured by the SF-36 physical function subscale, showed significantly higher scores with a swing and stance MPK than an NMPK [89,92].

Table 5 shows the EESs we developed related to activity outcomes.

\section{Cognitive Demand}

Cognitive demand outcomes are those associated with the physiological or perceived cognitive burden of locomotion. Physiological measures of cognitive demand reported in the MPK literature include distance traveled during a divided attention task, SSWS during a divided attention task, sway velocity during a divided attention task, serial subtraction test, Controlled Oral Word Association Test, and the Category Test. Perceived measures of cognitive demand that have been reported include the PEQ-A and the Prosthetic Cognitive Burden Scale (PCBS) [72-73,80,94-95].
Objective tests of divided attention have rarely reported significant differences in physiological measures of the cognitive demand required for ambulation when comparing MPKs and NMPKs [72-73,94-95]. No consistent measure of cognitive demand was used across the reviewed studies, but all included a measure of performance (e.g., head sway, accuracy of responses, number of correct responses) as subjects walked while performing a secondary (i.e., unrelated) task. The difficulty of the secondary tasks likewise varied across studies. No significant differences between the MPK and NMPK conditions were measured for users of swingonly MPKs walking on a treadmill [95], swing and stance MPK users walking in a laboratory [94], or swing and stance MPK users walking outside the laboratory over paved ground [73]. Hafner and Smith reported that subjects demonstrated a significant increase in outdoor SSWS without a significant change in divided attention task performance when using a swing and stance MPK compared with an NMPK [72]. Interestingly, they attributed this finding to those individuals originally considered to be limited community ambulators (i.e., MFCL-2).

In contrast to physiological measures of cognitive demand, significant differences in subject-reported cognitive demand required for ambulation have been described between prosthetic knees in the MPK literature [72$73,94]$. The use of swing and stance MPKs was found to significantly reduce subjective reports of cognitive burden, as evaluated through two ad hoc outcome measures, the PCBS [94] and PEQ-A [72-73]. Items in these questionnaires addressed several key issues, including subjects' perceived concentration, mental fatigue, and ability to multitask while walking.

Table 6 shows the EESs we developed related to cognitive demand outcomes.

Table 5.

Activity empirical evidence statements (EESs).

\begin{tabular}{lcc}
\hline \multicolumn{1}{c}{ EES } & Supporting Study & Level of Evidence \\
\hline 2-A. Use of swing and stance MPKs results in equivalent step counts, fre- & $2 \times$ Low $[73,91]$ & Low \\
quency of activity bouts, and activity bout duration when compared with & \\
use of NMPKs among individuals with unilateral TFLL. & \\
2-B. Use of swing and stance MPKs results in increased self-reported mobility & $3 \times$ Moderate $[79,89,92]$ \\
when compared with use of NMPKs among individuals with unilateral & $4 \times$ Low [72-73,88,90] & Moderate \\
TFLL. & \\
\hline MPK = microprocessor-controlled prosthetic knee, NMPK = non-microprocessor-controlled prosthetic knee, TFLL = transfemoral limb loss.
\end{tabular}


Table 6.

Cognitive demand empirical evidence statements (EESs).

\begin{tabular}{|c|c|c|}
\hline EES & Supporting Study & Level of Evidence \\
\hline $\begin{array}{l}\text { 3-A. Use of swing-only or swing and stance MPKs results in equivalent ability } \\
\text { to ambulate while performing secondary cognitive task when compared } \\
\text { with use of NMPKs among individuals with unilateral TFLL. }\end{array}$ & $\begin{array}{l}1 \times \text { Moderate }[94] \\
3 \times \text { Low }[72-73,95]\end{array}$ & Moderate \\
\hline $\begin{array}{l}\text { 3-B. Use of swing and stance MPKs results in decreased perception of cogni- } \\
\text { tive demand required for walking when compared with use of NMPKs } \\
\text { among individuals with unilateral TFLL. }\end{array}$ & $\begin{array}{l}1 \times \text { Moderate }[94] \\
2 \times \text { Low }[72-73]\end{array}$ & Moderate \\
\hline
\end{tabular}

\section{Gait Mechanics}

Gait mechanics outcomes are those associated with the temporal, spatial, kinematic, and/or kinetic parameters of gait. Measures of gait mechanics reported in the MPK literature include walking speed, spatial step symmetry, temporal step symmetry, kinematics, joint moment, joint power, GRF, and limb segment jerk [73,76-78,80-81,90,96-98].

Studies investigating temporal-spatial outcomes have reported significant differences between MPKs and NMPKs in one area (SSWS) and with one type of MPK (swing and stance). Three studies examined differences in SSWS on level ground as subjects used both swing and stance MPK and NMPK prostheses [78,81,90,98]. Two publications described a group of subjects $(n=8)$ that walked over an $11 \mathrm{~m}$ stretch of level terrain and adopted a significantly higher SSWS using a swing and stance MPK than an NMPK $[81,98]$. Similarly, a larger study of 19 subjects found that swing and stance MPK users walked significantly faster over $75 \mathrm{~m}$ level terrain than when they wore the NMPK [90]. In these studies, extended accommodation periods of $30 \mathrm{~d}[81,98]$ and $90 \mathrm{~d}$ [90] were provided to allow subjects to adjust to the different interventions. A third study of eight subjects showed no significant difference in SSWS between two different swing and stance MPKs and a single NMPK over a $0.25 \mathrm{mi}$ distance [78]. In this study, subjects were provided with approximately $10 \mathrm{~min}$ of accommodation time for each intervention. Similarly, two studies ( $n=10$ and $n=6)$ comparing swing-only MPKs with NMPKs in a single session (i.e., no extended period of accommodation) showed no significant change in SSWS between interventions $[76,80]$.

Neither temporal nor spatial measures of walking symmetry (i.e., step timing and step length, respectively) have been reported to consistently and significantly vary with prosthetic knee at SSWS $[73,76-78,80,98]$. Several studies comparing swing and stance MPKs with NMPKs have reported no significant temporal [77] or spatial $[73,77,98]$ differences in step symmetry at SSWS. However, Johansson et al., who compared temporal-spatial measures among two swing and stance MPKs and an NMPK with eight subjects, reported a significant increase in affected side-step time between one of the MPKs and the two other interventions [78]. This study also differed from the aforementioned studies in that subjects were accommodated for a relatively short period of time (i.e., $10 \mathrm{~min}$ ) and walked on a treadmill during assessment. Comparisons between swing-only MPKs and NMPKs in several studies showed no significant change in spatial [80] or temporal and spatial $[76,99]$ measures of symmetry.

Kinematic analyses of knee motion at SSWS have shown mixed and conflicting results. Three studies examined peak knee flexion during early stance, often termed "stance-phase knee flexion" [96-98]. Herr and Wilkenfeld completed an early pilot study of four subjects comparing a noncommercial swing and stance MPK with the subjects' customary NMPKs and observed increased knee flexion during stance while using the MPK [96]. However, they performed no statistical analysis. Subsequently, a comparison between a commercially available swing and stance MPK and NMPK in eight subjects with traumatic LLL showed no significant differences in stancephase knee-flexion angle at SSWS [98]. Conversely, a larger study of 15 subjects using the same two interventions found significantly increased knee-flexion angle during stance [97]. Segal et al. also examined peak knee flexion during swing phase and reported a significant [98] decrease in knee-flexion angle when subjects used the swing and stance MPK prosthesis compared with the NMPK. Kinematic measures for all of these studies were measured in similar environments (i.e., motion analysis laboratories) and used similar techniques.

The reviewed literature also included studies that used combined kinematic and kinetic analyses in an effort to evaluate changes produced by different knee 
components. Three studies examined differences in joint moments between swing and stance MPKs and NMPKs [78,97-98]. Two studies of 8 and 15 subjects, respectively, showed a significant increase in the prosthetic side knee moment while subjects used the MPK compared with the NMPK [97-98]. In both studies, subjects were accommodated to each intervention for an extended period of time before testing. Johansson et al., in a study with a shorter accommodation period $(10 \mathrm{~min})$, showed no significant difference in prosthetic side knee moment in early stance; however, a significant decrease in knee moment was measured at toe-off with the MPK compared with the NMPK [78]. Out of the aforementioned studies, only Johansson et al. evaluated peak hip moment in terminal stance [78]. They reported that users showed a significantly reduced prosthetic side hip moment at terminal stance with two different swing and stance MPKs compared with the NMPK.

Two studies that examined the joint moments associated with prosthetic ambulation also investigated differences in joint powers as they relate to the use of swing and stance MPK and NMPK prostheses [78,98]. Each study evaluated eight subjects in a gait laboratory. Johansson et al., evaluating interventions within a single session, reported significant differences in prosthetic side joint powers [78]. They reported that using MPKs resulted in significantly increased knee power at toe-off, significantly increased hip power at mid-to-late stance, and significantly decreased hip power at toe-off compared with the NMPK [78]. Segal et al., however, did not find any significant differences in prosthetic-limb joint kinetics [98]. They reported joint powers in the contralateral limb, the results of which suggested that the only change between the swing and stance MPK and NMPK condition occurred at the ankle [98]. Subjects showed a significantly lower maximum ankle power when using the MPK than when they used the NMPK.

Significant differences in gait outcomes associated with use of a swing and stance MPK prosthesis, including changes in GRF and jerk of the shank and thigh, appeared in one study each. In a study of eight subjects, Segal et al. reported that using a swing and stance MPK (compared with an NMPK) was associated with significantly decreased peak GRF on both the prosthetic and contralateral sides and a significantly increased time of peak GRF on the prosthetic side [98]. In another study of eight subjects, Johansson et al. reported that using either of two types of swing and stance MPKs was associated with significantly decreased root-mean-square jerk of the shank and thigh [78]. They reported that this indicated an improvement in the "smoothness of gait" when users walked in the MPK prosthesis.

Table 7 shows the EESs we developed related to gait mechanics outcomes.

\section{Environmental Obstacle Negotiation}

Environmental obstacle negotiation outcomes are those associated with ambulation across nonlevel surfaces, including uneven terrain, slopes, and stairs. Measures of environmental obstacle negotiation reported in the MPK literature include walking speed over uneven terrain, quality of stair descent, quality of slope descent, the Montreal Rehabilitation Performance Profile (MRPP), perceived ability to negotiate the obstacle, and performance on an obstacle course [72-73,83,88,90].

The influence of MPK technology on an individual's ability to negotiate environmental obstacles varies across the body of literature, depending on the obstacle (i.e., uneven terrain, stairs, incline), direction (i.e., ascent or descent), and type of MPK (i.e., swing and stance or stance only). The ability to walk over uneven terrain, quantified through the subject's time required to traverse an established obstacle course, was reported to significantly improve with the use of swing and stance MPKs $[72-73,83,90]$. The length of these courses varied from 12.2 [83] to 73.2 [72] $\mathrm{m}$ and included varying obstacle elements, including grass $[72-73,90]$, rocks $[72-73,90]$, sand $[72-73,90]$, wood chips [72-73], cement [72-73], and/or carpet [83]. Datta and Howitt measured the ability to negotiate uneven terrain with swing-only MPKs through subjective reports [88]. The majority of users (14 of 22) reported that the swing-only MPK improved their ability to walk over uneven terrain; one subject reported that the swing-only MPK made negotiation more difficult.

Two different research groups measured the ability to descend stairs and inclines while using a swing and stance MPK compared with an NMPK prosthesis [7273,90]. The influence of MPK technology on stair descent was measured with both the Stair Assessment Index (SAI) [72-73], an ad hoc observational scale, and the MRPP [90], an instrument designed to assess function in children with intellectual disability [100]. Both showed a significant improvement in the quality of stair descent gait patterns when subjects used the swing and stance MPK compared with the NMPK. Interestingly, in 
Table 7.

Gait mechanics empirical evidence statements (EESs).

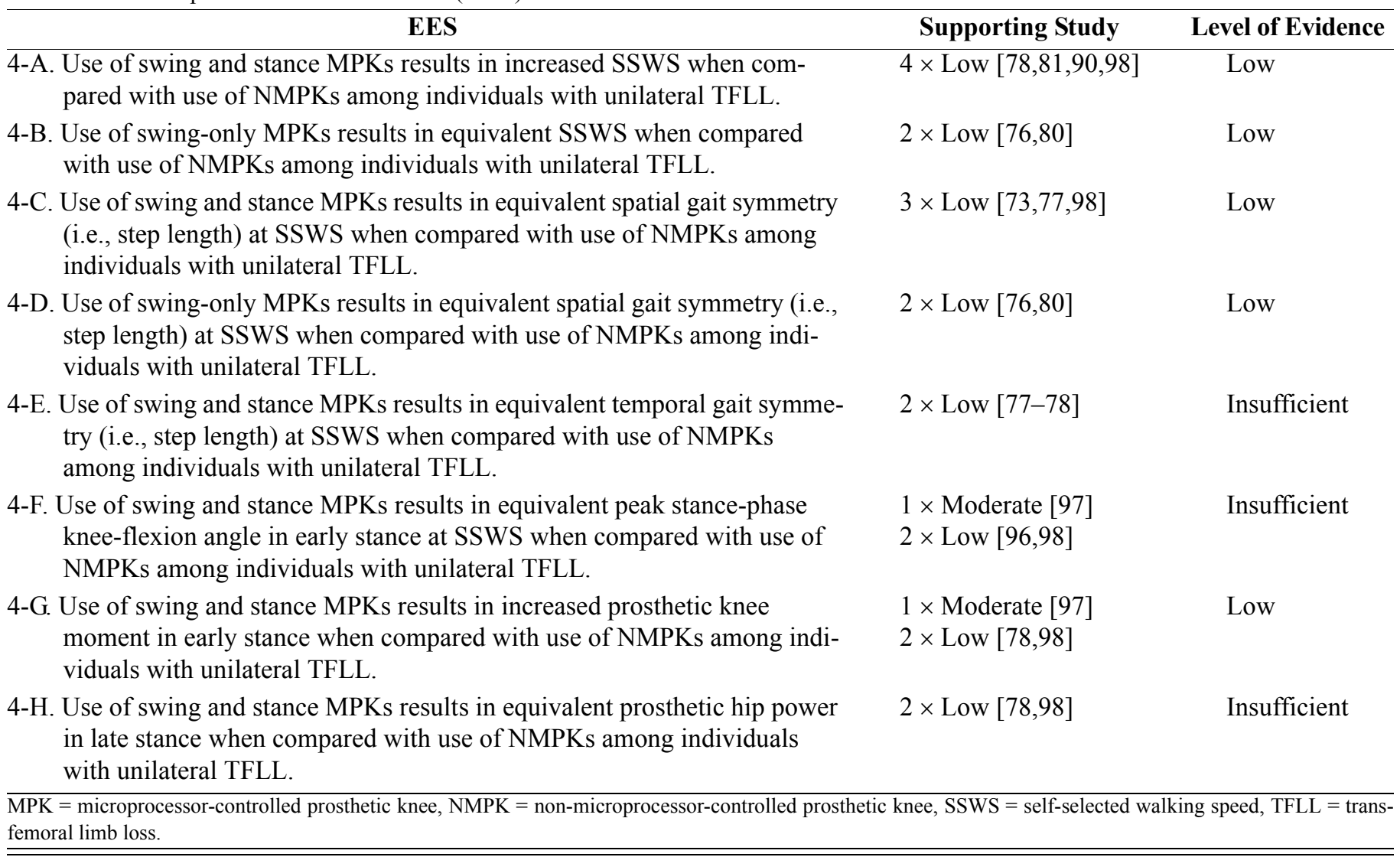

an ad hoc survey of swing and stance MPK users, Jepson et al. found that three of five reported that walking down stairs was more challenging than when using an NMPK [77]. In a similar survey of swing-only MPK use, they found that 5 of 22 subjects reported that the MPK improved stair descent, while the remainder of the subjects reported no difference [88].

Hafner and Smith [72] and Hafner et al. [73] used a tool similar to the SAI, the Hill Assessment Index (HAI), to quantify the quality of hill descent gait patterns along with the time required for subjects to descend a $28.2 \mathrm{~m}$ decline. Hafner et al. reported a significant decrease in the time of hill descent when subjects used a swing and stance MPK compared with an NMPK [73]. A follow-up publication revealed that HAI scores and time of hill descent were significantly improved in the MPK condition for MFCL-2 subjects, while hill descent time was improved for MFCL-3 subjects [72]. In a survey comparison of swing-only MPKs and NMPKs, Datta and Howitt revealed that the majority of users (13 of 22) reported an improved ability to negotiate slopes and hills in the MPK intervention, while one subject reported that the MPK made it more difficult [88].

Table 8 shows the EESs we developed related to environmental obstacle negotiation outcomes.

\section{Safety}

Safety outcomes are those associated with balance, balance-confidence, and the occurrence of adverse events such as stumbles or falls. Measures of safety reported in the MPK literature include the reported frequency of adverse events, subject-reported balance confidence, Activitiesspecific Balance Confidence (ABC) score, sensory organization test (SOT), and knee angle during gait perturbation [72-73,77,90,97,101-103].

The self-reported frequency of adverse events (i.e., stumbles and falls) has been used to quantify the differences in safety provided by MPK and NMPK interventions. In a study of 17 subjects receiving a swing and stance MPK following use of an NMPK, Hafner and 
JRRD, Volume 50, Number 3, 2013

Table 8.

Environmental obstacle negotiation empirical evidence statements (EESs).

\begin{tabular}{|c|c|c|}
\hline EES & Supporting Study & Level of Evidence \\
\hline $\begin{array}{l}\text { 5-A. Use of swing and stance MPKs results in increased walking speed on } \\
\text { uneven terrain when compared with use of NMPKs among individuals } \\
\text { with unilateral TFLL. }\end{array}$ & $4 \times \operatorname{Low}[72-73,83,90]$ & Low \\
\hline $\begin{array}{l}\text { 5-B. Use of swing and stance MPKs results in improved gait pattern during } \\
\text { stair descent when compared with use of NMPKs among individuals with } \\
\text { unilateral TFLL. }\end{array}$ & $3 \times \operatorname{Low}[72-73,90]$ & Low \\
\hline
\end{tabular}

Smith showed a significant decrease in the frequency of stumbles, semicontrolled falls, and uncontrolled falls in the study population [72]. Specifically, those individuals rated at the MFCL-2 level showed a significant decrease in the frequency of uncontrolled falls. Similarly, using data from a study of 19 users, Kahle et al. reported significantly fewer stumbles and falls while using the same swing and stance MPK compared with the NMPK [90]. In a third study consisting of five subjects, Jepson et al. found that two reported more stumbles and falls after receiving the MPK but that neither subject attributed the falls to the knee "giving way" [77].

Survey questions designed to elicit responses related to confidence and frustration with respect to balance, falls, and knee performance were also reported in the literature [72-73,101,103]. Comparison between a swing and stance MPK and NMPKs in a group of 17 subjects found a significantly reduced self-reported frustration with falls [72-73] and significantly higher confidence [72] when subjects used the MPK. Further, Hafner and Smith found significantly increased confidence in a smaller (i.e., $n=9$ ) MFCL-3 cohort [72]. Berry et al., in an ad hoc survey of 368 MFCL-3 individuals who had been prescribed a swing and stance MPK, found that users had significantly higher confidence in their MPK compared with the previous NMPK [101]. Lastly, in a case study of a $30 \mathrm{yr}$ old with traumatic amputation, Stevens and Carson found increased $\mathrm{ABC}$ scores after transitioning from an NMPK to a swing and stance MPK [103].

Changes in stability as a result of prosthetic knee have been investigated under static and dynamic conditions in the MPK literature. Kaufman et al. measured static balance, assessed by the SOT [104], in 15 subjects sequentially accommodated to an NMPK and then to a swing and stance MPK [97]. Tests conducted while subjects used the MPK produced significantly higher (i.e., better) individual and composite SOT scores. Blumentritt et al. assessed dynamic balance by measuring knee angle during simulated gait disruptions in a pilot study of three experienced individuals with amputation using two different types of NMPKs and a swing and stance MPK [102]. They observed a decreased knee-flexion angle in the MPK compared with the NMPK. They suggested that this was indicative of improved balance in the MPK condition.

Table 9 shows the EESs we developed related to safety outcomes.

Table 9.

Safety empirical evidence statements (EESs).

\begin{tabular}{|c|c|c|}
\hline EES & Supporting Study & Level of Evidence \\
\hline $\begin{array}{l}\text { 6-A. Use of swing and stance MPKs results in decreased number of subject- } \\
\text { reported stumbles and falls when compared with use of NMPKs among } \\
\text { individuals with unilateral TFLL. }\end{array}$ & $4 \times$ Low $[72-73,77,90]$ & Low \\
\hline $\begin{array}{l}\text { 6-B. Use of swing and stance MPKs results in decreased subject-reported } \\
\text { frustration with falling when compared with use of NMPKs among } \\
\text { individuals with unilateral TFLL. }\end{array}$ & $2 \times \operatorname{Low}[72-73]$ & Insufficient \\
\hline
\end{tabular}




\section{Preference and Satisfaction}

Preference and satisfaction outcomes are those associated with a user's selection of or preference for a prosthetic knee as well his or her overall contentment with the intervention. Measures of preference and satisfaction reported in the MPK literature include intervention selection and subject-reported satisfaction [72-73,77,80-81,88,90].

Reports of preference and satisfaction in the MPK literature indicate that subjects favor swing-only and swing and stance MPK devices over the NMPK interventions with which they were compared. Two studies allowed subjects to choose their intervention of choice following the test protocol. As few as 74 [90] and as many as 82 [73] percent of subjects selected a swing and stance MPK over an NMPK. In these studies, the MPK was the most recently worn intervention. However, an unknown percentage of subjects in a randomized trial also provided unsolicited preference for a swing and stance MPK compared with a swing and stance NMPK [81]. Note that the assessment of preference was universally performed immediately following testing. In a 6 mo follow-up, Jepson et al. showed that three of five individuals who had been provided with a swing and stance MPK in the study were no longer using that intervention [77]. No other long-term follow-ups of preference were conducted.

Reports of preference related to swing-only MPKs compared with NMPKs were less common but reported similar findings. In a retrospective assessment of preference by swing-only MPK users, Kirker et al. showed that significantly more individuals preferred the MPK they were currently using to their previously used NMPK [80]. In a prospective trial of swing-only NMPK users that were switched to swing-only MPKs, Datta and Howitt reported that 1 of 22 users would happily wear his or her NMPK device again after using the MPK [88].
Subject-reported satisfaction was similarly reported to be related to prosthetic knee type. Two studies noted the results of the first question of the PEQ [50], which asks the subject, "Over the past $4 \mathrm{wk}$, how happy have you been with your prosthesis?" [73,90] This question has not been independently validated as a stand-alone tool [50]. In both studies, the swing and stance MPK was found to score significantly higher (i.e., better) in satisfaction than the NMPK $[73,90]$.

Table 10 shows the EESs we developed related to preference and satisfaction outcomes.

\section{Economics}

Economic outcomes are those associated with the financial expense or cost-effectiveness of the intervention. Measures of economic outcomes reported in the MPK literature include prosthesis acquisition costs, total social costs, and incremental cost-effectiveness ratios $[89,92,105]$.

Economic analyses of MPK and NMPK technology in the published literature, conducted primarily in Europe, have reported the costs associated with procuring and using different types of prosthetic knees $[89,92,105]$. Costs associated with the acquisition of the prosthesis (in euros $(€)$ are a common element among three studies conducted in Italy [89], the Netherlands [92], and Sweden [105] and were derived from either national cost estimates [92] or patient and practitioner interviews $[89,105]$. Mean acquisition costs of a swing and stance MPK ranged from $€ 17,003$ ( $\$ 21,834)$ [105] to $€ 19,270$ $(\$ 26,012)$ [92], while mean acquisition costs of NMPKs spanned $€ 3,600(\$ 4,328)$ [89] to $€ 8,057(\$ 10,876)$ [92]. Differences in acquisition costs were reported to be significantly different between the prosthetic knees $[89,92]$.

Table 10.

Preference and satisfaction empirical evidence statements (EESs).

\begin{tabular}{lcc}
\hline \multicolumn{1}{c}{ EES } & Supporting Study & Level of Evidence \\
\hline 7-A. Use of swing and stance MPKs results in increased subject-reported prefer- & $4 \times$ Low $[73,77,81,90]$ & \\
ence when compared with use of NMPKs among individuals with unilateral \\
TFLL.
\end{tabular}


Two studies considered the overall social costs associated with the prosthesis $[89,92]$. This includes the costs of acquisition, inpatient care, outpatient care, hospital, housekeeping, transportation, adaptive technology, and loss of productivity. Annualized social costs for the MPK ranged from $€ 13,334(\$ 16,032)$ [89] to $€ 14,006$ $(\$ 18,906)$ [92] and $€ 12,917$ (\$15,531) [92] to $€ 13,384$ $(\$ 16,092)$ [89] for the NMPK. These differences in costs were not found to significantly differ between the MPK and NMPK $[89,92]$.

Two studies reported incremental cost-effectiveness ratios (€/quality adjusted life year [QALY]) comparing swing and stance MPKs with NMPKs [89,105]. Estimates for the cost $(€)$ per QALY associated with the use of a swing and stance MPK compared with an NMPK varied between $€ 3,218$ (\$4,132) [105] and $€ 35,971$ $(\$ 43,251)[89]$ depending on the cost of the NMPK.

Table 11 shows the EESs we developed related to economic outcomes.

\section{Health and Quality of Life}

Health and QOL outcomes are those associated with a user's overall health and perceived general well-being. Measures of health and QOL reported in the MPK literature include the SF-36 general health subscale, PEQ wellbeing subscale, and QALYs [72-73,79,92,105].
Outcomes related to general health were reported to differ based on the type of measure used to evaluate the construct of health. Two studies that reported the SF-36 general health subscale found increased scores (i.e., improved health) when using a swing and stance MPK compared with the NMPK, but these findings were not significant $[73,92]$. Three studies that reported health using the PEQ well-being subscale similarly found increased (i.e., improved well-being) scores associated with use of a swing and stance MPK after wearing an NMPK $[72-73,79]$. Two of the studies reported this difference between interventions as significant [72,79].

Health effectiveness of the prosthetic interventions was also determined through the EuroQol EQ-5D [106]. Two studies computed QALY from the EQ-5D utility weights for each intervention [89,105]. The QALY ranged from 3.55 [89] to 5.98 [105] for the MPK and 3.13 [89] to 3.60 [105] for the NMPK. Gerzeli et al. found a significant difference in QALY between the MPK and NMPK [89]. The health effectiveness measures obtained in these studies were used to compute incremental cost-effectiveness ratios, values intended to be used by healthcare agencies to determine provision decisions.

Table 12 shows the EESs we developed related to health and QOL outcomes.

Table 11.

Economic empirical evidence statements (EESs).

\begin{tabular}{|c|c|c|}
\hline EES & Supporting Study & Level of Evidence \\
\hline $\begin{array}{l}\text { 9-A. Prescription of swing and stance MPKs results in increased prosthesis acqui- } \\
\text { sition costs compared with NMPKs among individuals with unilateral TFLL. }\end{array}$ & $\begin{array}{l}2 \times \text { Moderate }[89,92] \\
1 \times \text { Low }[105]\end{array}$ & Moderate \\
\hline
\end{tabular}

Table 12.

Health and quality of life empirical evidence statements (EESs).

\begin{tabular}{lll}
\hline \multicolumn{1}{c}{ EES } & Supporting Study & Level of Evidence \\
\hline 8-A. Use of swing and stance MPKs results in equivalent self-reported general & $1 \times$ Moderate [92] & $1 \times$ Low [73] \\
health compared with NMPKs among individuals with unilateral TFLL. & $1 \times$ Moderate [79] & Moderate \\
8-B. Use of swing and stance MPKs results in increased self-reported well- & $2 \times$ Low [72-73] \\
being compared with NMPKs among individuals with unilateral TFLL. & $1 \times$ Moderate [89] & $1 \times$ Low [105] \\
8-C. Use of swing and stance MPKs results in increased QALY compared with & Moderate \\
NMPKs among individuals with unilateral TFLL. & \\
MPK = microprocessor-controlled prosthetic knee, NMPK = non-microprocessor-controlled prosthetic knee, QALY= quality adjusted life year, TFLL= transfemoral \\
\hline limb loss.
\end{tabular}




\section{DISCUSSION}

Systematic reviews are widely recognized as one of the highest forms of evidence and a valuable component of EBP [67,107]. The methodical approach to the collection, evaluation, and synthesis of a body of literature inherent to a systematic review provides the means to address a focused and relevant clinical question. Here, that question was, Does the prescription, fit, and use of MPKs lead to changes in outcomes for individuals with unilateral TFLL when compared with NMPKs? Thus, the goal of this review was to systematically identify, assess, and interpret the body of scientific literature that compares MPK and NMPK and to synthesize the knowledge obtained through that process into clinically useful empirical evidence. Further, we hoped that such evidence could be used to develop clinical guidelines, establish research priorities, inform healthcare policy, and advance knowledge related to O\&P research [71].

The identification and collection process produced 27 peer-reviewed scientific publications that met the selection criteria and were included in this review. While this is fewer than the number of publications $(n=240)$ included in one recent systematic review of O\&P outcomes [108], it is consistent with the number of publications $(n=25-34)$ that have appeared in others performed using similar strategies [109-112]. The number of publications included in this review is also similar to a 2004 Cochrane Review of prosthetic feet that included 29 total publications [113-114].

As previously noted, the population of study across the reviewed body of literature was predominantly individuals with an amputation due to nondysvascular etiologies (trauma, tumor, osteomyelitis, congenital, or other). This contrasts sharply with the general population with amputation, wherein the most common $(>80 \%)$ cause of LLL is vascular disease [1-2]. While this may limit the generalizability of the evidence obtained in this review to a portion of the overall population with amputation, note that patients with amputation with vascular causes are not commonly fit with MPKs [62]. Perhaps of greater effect of the clinical relevance of this review is the mobility level of included subjects. Historically, MPKs have been prescribed for MFCL-3 or -4 and select MFCL-2 patients with the "cardiovascular reserve, strength, and balance to use the prosthesis" [62]. The subjects described in those studies reviewed here all fall into one of these classifications. Thus, the outcomes presented in the review likely represent those that may be achieved by individuals most commonly fit with MPKs. Readers are further advised to review the demographics of the individual studies (Table 3) reflected in each EES when extrapolating the findings to a specific patient or patient population.

We specified the intervention of focus in this review to be MPKs. However, it should be acknowledged that the reviewed body of literature included several different types and several different models of MPKs. As noted previously, both swing-only and swing and stance MPKs were studied in the reviewed literature. We discovered four commercially available models of MPKs studied within this body of literature. These included the Compact C-Leg, SmartIP, RHEO KNEE, and Adaptive Knee (Endolite; Miamisburg, Ohio). Although we found the Cleg and the SmartIP to be the focus of multiple studies (i.e., 17 and 6, respectively), the RHEO KNEE and Adaptive Knee (in their commercialized forms) were studied once each.

The large number of outcome measures (i.e., more than 45 unique measures in 9 outcome areas) described in the reviewed publications was indicative of the breadth of the reviewed literature. While this diversity contributed to a greater number of EESs, the heterogeneity of outcome measures used across the studies also reduced the level of evidence available to support the derived EESs. We considered the absence of homogenous use of outcome measures across this body of literature to be one of the primary reasons that the evidence was not stronger than that presented here. However, identification of these outcome topics and the associated measures offers the potential for other investigators to contribute greatly to the overall evidence in this area by augmenting the reviewed findings with additional research.

\section{Empirical Evidence Statements}

The following sections discuss the findings of the systematic review and the derived EESs within the context of existing literature related to the outcome topics.

\section{Metabolic Energy Expenditure}

Despite similar metabolic energy requirements as individuals without amputation in static standing [30], the ambulation of individuals with TFLL is 27 to 89 percent less efficient than nondisabled controls [30,32,115-117]. This difference has been attributed to excessive muscular cocontraction, atypical trunk motion, and/or compensatory limb movements [115]. Due to the significantly increased 
metabolic cost required for prosthetic ambulation, lowerlimb prosthetic interventions are often designed to mitigate these costs. For example, an MPK is intended to constantly adjust the knee-joint resistance in order to accommodate a wider range of walking speeds and facilitate a more efficient gait [62]. Theoretically, this should reduce the energy required by the user to accelerate and decelerate the limb during swing phase. Similarly, a swing and stance MPK should help stabilize the user during single-limb stance, thus reducing the usual energy required for the muscular cocontractions and/or accessory bodily movements needed to maintain balance. Given that most prostheses are "tuned" by the prosthetist for the patient's SSWS, an MPK might be expected to reduce metabolic energy expenditure most when he or she walks at speeds above or below the SSWS. However, the available peer-reviewed literature indicates that $\mathrm{O}_{2}$ cost is equivalent between swing and stance MPKs and NMPKs across a range of walking speeds (EES 1-A).

One type of MPK (swing and stance) was found to reduce metabolic energy expenditure through a decrease in $\mathrm{O}_{2}$ rate at SSWS (EES 1-B). However, the studies that contributed to this finding [78,82-83] all shared a common trait: a relatively short period of accommodation to the prosthetic interventions (no more than a few minutes). Thus, it appears that when little or no accommodation time was provided to subjects prior to testing, small but significant differences in $\mathrm{O}_{2}$ cost [83] and rate [78,82-83] emerged. However, when longer periods of accommodation were provided, significant differences in measures of metabolic energy expenditure did not appear $[79,81]$. While this theme did not extend to studies of swing-only MPKs, it is one worth additional exploration.

Comparisons among studies of metabolic energy expenditure were complicated by the variety of outcome measures used by study investigators. Six studies assessed $\mathrm{O}_{2}$ rate, which measures the level of physical effort required to perform an activity over a period of time [33]. Four other studies [76,79,81,83] reported results in terms of $\mathrm{O}_{2}$ cost, which describes the amount of energy used to perform the task of walking over an assigned distance [33]. $\mathrm{O}_{2}$ cost is generally preferred as a measure of gait efficiency because it accounts for walking speed, while $\mathrm{O}_{2}$ rate does not. This may be an important factor to consider because research suggests that individuals with LLL decrease their walking speed to maintain an $\mathrm{O}_{2}$ rate that is equal to that of individuals without amputation [117]. Therefore, measuring $\mathrm{O}_{2}$ rate without considering $\mathrm{O}_{2}$ cost and SSWS may be misleading. Orendurff et al. elected to use the net $\mathrm{O}_{2}$ cost, which extracts the resting $\mathrm{O}_{2}$ cost from that associated with the activity [81]. This may be important because resting $\mathrm{O}_{2}$ cost is a noted contributor to gross $\mathrm{O}_{2}$ consumption during ambulation [118] but is not expected to be affected by a prosthetic intervention. Thus, removing resting $\mathrm{O}_{2}$ cost from the analysis may allow subtle changes in metabolic energy expenditure resulting from use of a component to be more easily detected.

Note that the significant differences in metabolic energy expenditure reported in this body of literature in most cases exceeded the 3 to 5 percent normal variation of $\mathrm{O}_{2}$ consumed during submaximal exercise in nondisabled individuals [119]. Because Buckley et al. suggested that such changes are clinically relevant [75], the changes produced by the swing and stance MPK may be interpreted to be both clinically and statistically significant.

The majority of the reviewed metabolic energy expenditure studies incorporated treadmill ambulation tests $[75-76,79,80,82-84]$, but several used overground ambulation tests $[77,78,81]$. While no clear pattern in the results emerged between those using treadmill versus overground ambulation, it has been established that the metabolic costs for treadmill ambulation are greater than overground walking among nondisabled individuals [120], patients with stroke [121], and individuals with TFLL [122]. Thus, take caution when directly comparing the results of treadmill and overground ambulation tests.

One important consideration in the collection and interpretation of metabolic energy expenditure data is the ecological validity of the experiment. Most measures of $\mathrm{O}_{2}$ uptake (i.e., those using standard gas oximetry techniques) require prolonged ambulation in order to reach a steady state. Once it is achieved, activity must be maintained for a period of time to allow for adequate sampling of the expired gases. The studies included in this review reported testing times that ranged from 3 to $16 \mathrm{~min}$. Interestingly, the usual activity bout duration among individuals with TFLL has been reported to be between 1 and 2 min consisting of 17 to 34 steps [91]. Thus, while metabolic experiments in this body of literature may assess the physiological capacity of individuals with TFLL, they are often conducted under atypical conditions that may not well reflect how the prosthesis is used by representative individuals. Kaufman et al. described an alternative approach to address this mismatch between test environment and real world conditions [79]. In this study, investigators used a DLW technique [85] to 
estimate TDEE in the prosthesis users' free-living environment. This technique has been used across a wide range of populations and is considered to be a criterion measure of physical activity [123]. While Kaufman et al. reported that TDEE was equivalent between swing and stance MPKs and NMPKs, PAEE increased with the use of swing and stance MPKs, leading to the conclusion that the amount of activity in which those subjects engaged increased with that intervention [79]. Although further work is needed to replicate and validate these findings, this appears to be a promising technique to complement or address the ecological limitation of laboratory-based metabolic energy expenditure testing.

Another alternative to traditional, physiological measures of metabolic energy expenditure are PROs. Kaufman et al. reported that using a swing and stance MPK was associated with a decreased RPE when compared with using an NMPK [79]. While such findings from a single study may not contribute to the formulation of an EES in this review, the knowledge that RPE decreased [79] and other physiological measures of metabolic energy expenditure did not change after longer periods of accommodation $[79,81]$ may indicate that traditional measures are not sensitive enough to capture the differences subjects perceived between MPKs and NMPKs. Recently renewed interest in other means to assess metabolic energy expenditure, such as dynamic walking theory [124-125], may also provide insight and unique methodologies to further evaluate metabolic energy expenditure among individuals with TFLL and the effect of select componentry.

Lastly, as the number of commercially available MPKs increases, clinicians will have to decide not only between MPKs and NMPKs but also among the variety of MPKs available. While not informing directly upon the primary question of interest in this review, Chin et al. found no statistically significant difference in $\mathrm{O}_{2}$ rate between a swing and stance MPK and a swing-only MPK across a range of walking speeds [126]. Similarly, subjects' most efficient walking speed was equivalent between the two knees [126]. Johansson et al. also reported no significant difference in $\mathrm{O}_{2}$ rate between two different swing and stance MPKs [78]. Thus, while it appears that different types of MPKs may not change metabolic energy expenditure, more research is needed to confirm this finding.

\section{Activity}

As noted previously, there are many physical impairments associated with TFLL. These impairments are often so severe that only 50 to 72 percent of individuals with TFLL are reported to achieve ambulation with a prosthesis $[6,8,14,127]$. Those that do may require an additional walking aid (i.e., canes or crutches), particularly for functioning outside of the home environment $[6,8,128-129]$. While eight studies identified in this review included assessments of activity (Table 3), they were all published within the last 3 yr (2006-2009), perhaps indicating an elevated interest in assessing outcomes in this area.

Ambulatory individuals with TFLL have been found to take anywhere from 1,069 [41] to 2,675 [91] steps/d. This is greater than the minimum of $600 \mathrm{steps} / \mathrm{d}$ thought to be necessary to sustain an independent lifestyle in a single-level residence with moderate family or social support and in some cases above the 1,100 to 1,450 steps/d recommended for independent living [40]. This is well below the average number of steps reported for both "highly active" and "moderately active" older community-dwelling adults (i.e., 12,660 and 7,596 steps/d, respectively) and even below those classified as "inactive" (i.e., 3,893 steps/d) [130]. Further, it has been reported that steps taken by individuals with TFLL appear as very short bouts lasting 1 to $2 \mathrm{~min}$ and consisting of $\leq 17$ steps [91]. This is consistent with reports that most (75\%) individuals with TFLL walk $<0.5 \mathrm{~km} / \mathrm{d}$ and 16 percent walk $>2 \mathrm{~km} / \mathrm{d}$ [128]. What is relatively unknown is how different prosthetic interventions, such as prosthetic knees, influence this type of activity.

The evidence reviewed suggests that activity measures such as step count, activity bout duration, and the frequency of activity bouts, which represent the amount of activity performed, do not appear to significantly differ by prosthetic knee type (EES 2-A). Though contrary to several investigators' hypotheses [73,91], it would appear that the use of a swing and stance MPK does not increase the amount or frequency of activity that is performed. The most straightforward explanation is that individuals with TFLL, like anyone else, have a basic amount of ambulatory activity (i.e., moving around the house, going to work, going to the store) that they conduct on a normal basis and that a change in the prosthesis does not encourage them to change the amount or frequency of their daily patterns. Logically, a change in the volume of activity would result if the prosthetic component addressed some 
functional limitation that prevented individuals from engaging in a desired activity that required a greater number of steps to perform. The subjects of these activity studies were established individuals with amputation, and may have adapted their lives (and activity patterns) to meet their needs. Therefore, use of a swing and stance MPK may not have produced the hypothesized change in volume of activity.

Conversely, it might be argued that while the volume of activity may not change as the result of a prosthetic intervention, the type of activity or the ease with which activity is performed may change. With the added stancephase stability afforded by swing and stance MPKs, subjects may be more likely to engage in activities that they had previously not felt safe or confident performing. This would not necessarily be reflected by an increase in the amount or frequency of activity as assessed through measures of step counts but would indicate a relevant clinical change in activity. This change in type of activity performed or the ease with which it is performed may be reflected in EES 2-B, which describes an increased patient-reported mobility with the use of a swing and stance MPK. Many of the questions in the contributing questionnaires asked about types of activities performed or the ease with which they were performed rather than how much activity was performed. Therefore, it may be that the use of a swing and stance MPK is more likely to increase the ease with which activity is performed or change the types of activities that are performed rather than the amount.

Another way that a change in activity may be measured is through the MFCL, the practitioner's assessment of an individual's ability or potential to ambulate. Several publications in this reviewed body of literature suggested that the use of swing and stance MPKs may increase the MFCL among MFCL-2 and -3 patients when compared with the use of NMPKs $[72,90]$. Kahle et al. found that four of nine study subjects, originally evaluated as MFCL2, were re-evaluated as MFCL-3 upon conclusion of the trial [90]. Hafner and Smith similarly found that four of eight MFCL-2 subjects improved to MFCL-3, while three of nine MFCL-3 subjects improved to MFCL-4 [72]. The relevance of these findings is that subjects who were previously considered unable to traverse more than low-level environmental barriers (MFCL-2) were able to achieve unlimited community ambulation and could walk with variable cadence (both MFCL-3 traits) after exposure to the MPK. Although the causal connection between MPK use and MFCL change was not demonstrated in these studies, these observations are nonetheless interesting.

The prospect that technology may provide the means to alter less-functional users' ambulatory potential challenges certain clinical and reimbursement paradigms. Historically, the lower a patient's ambulatory potential, the simpler and less expensive the provided prosthesis [131]. More complex and more expensive prosthetic technology has been typically reserved for the most active individuals [55]. The results reported by Kahle et al. [90] and Hafner and Smith [72] would appear to challenge this standard. For example, one commonly cited requirement for the prescription of (and reimbursement for) an MPK is that the patient demonstrates the ability to walk with a variable cadence. If not, the patient is assigned to MFCL-2 and is typically not considered eligible for an MPK. However, the preliminary results by Kahle et al. [90] and Hafner and Smith [72] may suggest that it is the use of the MPK that allows select patients to achieve variable cadence. Thus, these patients may be denied access to the very technology that may allow them to qualify for it. Though it is premature to suggest that this paradox exists based on the existing evidence, these findings merit further investigation.

Another possible explanation for the evidence not showing the hypothesized change in step activity with the different types of prosthetic knees may be related to the period of monitoring. Selecting an appropriate step count sampling interval is needed to represent an individual's true activity and reliably extrapolate beyond the period of measurement. Tudor-Locke et al. [132] reported that $3 \mathrm{~d}$ worth of data collection were sufficient to provide a reliable estimate of weekly step counts, while $7 \mathrm{~d}$ are recommend in order to establish a reliable estimate of monthly activity [133]. For an accurate estimation of annual step counts, Kang et al. recommended a minimum of $30 \mathrm{~d}$ of continuous monitoring or $14 \mathrm{~d}$ of random monitoring [134]. Interestingly, Togo et al. stated that annual step counts can be estimated with as few as $8 \mathrm{~d}$, provided that they are acquired with random and seasonal sampling; otherwise, they recommended up to $105 \mathrm{~d}$ of consecutive observations [135]. The two studies of prosthetic knees relevant to the EES developed in this review collected continuous step data for 1 [91] and 2 [73] wk periods, respectively. Thus, while consistent with recommendations by the device manufacturer [93], these results should be considered reasonable estimates of monthly activity. One area of future study may be to examine 
longer sampling periods to see whether the results reported in the literature are confirmed over longer time intervals.

Although readers may question the logic of presenting several alternative hypotheses regarding these activity outcomes, one reason for such considerations is the presence of contradictory self-reported evidence related to this outcome topic. For individuals with LLL, the most impaired factor of HRQL is reported to be physical function or mobility [136-138]. Notably, this review discovered that one of the most commonly reported outcomes associated with use of an MPK (compared with an NMPK) was an increase in self-reported mobility (EES 2-B). This finding creates an interesting dichotomy between physiological or biomechanical tests and selfreported outcomes. Perhaps most importantly, it stresses the importance of and need for including both types of measures when evaluating outcomes involving subjects. Doing so may reveal subtle differences in perspective, stimulate new directions of scientific inquiry, and encourage the use of new methodological approaches. Such approaches to studying activity level might include methods like PowerLine Positioning [139], neural network recognition of motor activity classes [140], and nonlinear analysis techniques [141].

\section{Cognitive Demand}

Walking is generally regarded as an activity that requires minimal attention [142-143]. However, ambulation with a transfemoral prosthesis may necessitate greater concentration due to the loss of traditional peripheral sensorimotor structures in the lower limb, an increased reliance on visual information for afferent input $[29,46]$, and the need to focus on stabilizing the prosthetic knee with the remaining proximal musculature $[29,46]$. Further, the elevated cognitive burden associated with ambulation in nondisabled individuals over differing terrain conditions [144] or during the performance of concurrent, unrelated cognitive tasks [145] is likely to be as much or more of a concern to individuals with LLL. The addition of MPC to a prosthetic knee is often assumed to decrease the cognitive attention required for ambulation [146]. However, the current empirical evidence, as established through this systematic review, indicates that this assertion is substantiated by PROs of perceived cognitive demand (EES 3-B) and is not yet well established through physiological or biomechanical measures of cognitive demand (EES 3-A).
One reason for the inconsistency in these findings may be due to the challenges associated with objectively measuring cognitive demand. Research studying the cognitive (sometimes referred to as "attentional") demands associated with an activity frequently use a dual taskparadigm where the primary task (ambulation) is performed concurrently with a secondary task (e.g., answering questions) of some mental difficulty [147]. The extent to which performance on the primary and/or secondary tasks degrades when performed together is then used as a measure of cognitive demand. One challenging element in conducting experiments of this nature is in the selection of a concurrent, secondary task that is sufficiently difficult so as to interfere with the automaticity of the primary task. Further, the experimental control of the primary and secondary tasks should be managed to provide an assessment of either the difficulty in conducting one or more cognitive tasks while simultaneously conducting a performance task (goal 1) or evaluation of the change in primary task performance caused by introducing one or more secondary tasks (goal 2). To measure the former, the performance task should be kept constant (e.g., requiring subjects to walk at a constant speed for all conditions) while the cognitive tasks of varying difficulty are applied. The results of the cognitive tests (when compared with results obtained when subjects are not performing the primary task) may then be used to assess the additional cognitive demand required to conduct the primary task. To measure the latter, the performance of the primary task is allowed to change (e.g., subjects are allowed to vary their walking speed) and controlled secondary cognitive tasks are applied to examine the influence of distraction on the primary task. The addition of different interventions, such as the MPK and NMPK prostheses, increases the complexity of the testing, and care must be taken to properly control the experimental conditions.

Of those studies that included primary and secondary tasks, Heller et al. [95] and Williams et al. [94] selected an experimental design similar to that noted previously by goal 1. Both controlled the performance task (walking speed) while assessing the outcomes of a variety of secondary tasks (e.g., response accuracy and/or body sway). Neither group reported significant differences between interventions (i.e., MPK or NMPK), but Williams et al. suggested that the primary and secondary tasks selected may not have been of sufficient difficulty to challenge the subjects [94]. They suggested that the potential benefits provided by swing and stance MPKs may become detectable under more 
challenging primary task conditions such as negotiating environmental obstacles. Similarly, they proposed that more difficult secondary cognitive tests could be selected to challenge the subjects. As previously noted, the selection of these tasks may be a challenge because we are unaware of published guidelines or recommendations to assist investigators in this process. However, considerations may include the type of resources used to address the task (e.g., memory, visuospatial, and/or executive function), task difficulty (e.g., a 7-digit vs 3-digit reverse numbers test), the capabilities of the subjects (e.g., individuals with dysvascular amputations may have cognitive impairments that influence task performance), and environmental factors (e.g., low-light conditions may make walking more difficult).

In contrast to Williams et al. [94], Hafner et al. [73] described an experimental design similar to goal 2 described previously. In this study, they evaluated a prosthesis user's primary task performance, as measured by time and distance, while the user performed a secondary mental loading task (i.e., reverse numbers test). Subjects were allowed to vary either or both the primary and secondary tasks. Such a situation introduces a challenge when interpreting the relative changes in performance. For example, how does one compare the results of two subjects, one who walks farther with more errors and one who travels a shorter distance with fewer errors? The first might not be as distracted by the cognitive test as the second, so a comparison of the distance traveled may not be appropriate. Given that each individual may prioritize the primary and secondary tasks differently, understanding a population result is challenging A similar example was found in an abstract by Meier et al., wherein obstacle course time with and without a mental loading task (serial subtraction) was assessed for different knee-joint conditions (i.e., MPK and two NMPKs) [148]. While the time did not differ significantly between the MPK and NMPK conditions, the test accuracy was not reported and so the combined effect of the primary and secondary tasks was unknown. In future studies, it may be beneficial to group subjects by relative accuracy on the cognitive test scores so that comparisons are appropriately made among subjects who were attentively challenged to the same degree.

Properly managing groups in cognitive demand research may also be important for other reasons. Hafner and Smith reported that MFCL-2 subjects demonstrated a significant increase in outdoor SSWS without a significant decrease in performance on the divided attention task while using a swing and stance MPK compared with an NMPK [72]. However, studied MFCL-3 subjects showed equivalent speed and accuracy under both prosthetic knee conditions. This finding suggests that the influence of MPKs on locomotor performance may vary based on specific individual characteristics, such as MFCL. Although further study is warranted to confirm this finding, it may again suggest that technological advances in prosthetics, such as knee MPC, may be beneficial for patients not previously considered to be ideal candidates for that technology under typical prescription criteria.

The study of cognitive demand and MP technology may also require other study design considerations. The attentional requirements of walking have been reported to vary within a gait cycle in both individuals with LLL [47] and without amputation [149]. As noted previously, MPC in an MPK is active during select phases of the gait cycle and varies with each specific model. As such, analysis of in-phase attentional demand may reveal differences among prosthetic knees that are "washed out" when the entire gait cycle is evaluated. Note that all four cognitive demand studies included in this review used tests designed to measure cognitive demand across multiple gait cycles and did not focus on specific phases. Future research designs may consider assessment of cognitive demand within the gait cycle. Such designs would require the use of reaction-time methodologies rather than those that measure the number of errors or answers that can be provided over an extended testing protocol. Such techniques may better inform how MPKs differ when the MP is active during the swing and/or stance phases of gait.

An additional consideration for future cognitive demand research may be the inclusion of a single-task condition in addition to the dual-task condition. In the single-task condition, the secondary task is performed on its own (i.e., in a seated or standing position), ideally with a high degree of proficiency. This establishes a baseline condition for the secondary task that allows for a relative assessment of its degradation after transitioning to the dual-task condition. This is similar to establishing and removing the basal metabolic rate prior to analyzing metabolic energy data and may allow for a more detailed analysis of the difficulty and hence interference caused by the secondary task during dual-task testing.

Lastly, the instructions provided to study subjects may guide or influence their attentional focus and subsequently their measured performance in the primary or secondary 
tasks. For example, subjects may prioritize tasks differently if told to "walk as quickly as possible" than when told to "try to answer questions as quickly as possible." It is likely that, if provided the former instructions, subjects would prioritize the primary task, and if provided the latter, prioritize the secondary task. Unfortunately, none of the reviewed studies referenced the explicit instructions provided to study subjects; therefore, the relative prioritization is unknown. In the future, investigators may wish to include such information to allow readers to better understand subjects' potential for selectively allocating cognitive resources.

\section{Gait Mechanics}

In addition to increased metabolic energy expenditure, LLL has been well documented to be associated with reduced SSWS [150]. As with metabolic limitations, this deficit worsens at more proximal levels of amputation $[30,33,151]$. However, it is often hypothesized that modern prosthetic interventions (e.g., MPKs) have the potential to address the physical challenges associated with LLL and therefore increase a user's SSWS compared with NMPKs. However, the evidence obtained from this review suggests that specific types (i.e., swing and stance) of MPKs have shown such potential (EES 4A). In contrast, users appear to select similar SSWS when wearing either swing-only MPKs or NMPKs (EES 4-B). Thus, MPC of stance phase may be related to the reported changes in SSWS. One possible explanation may be that individuals with TFLL choose to walk at a slower SSWS to avoid falling and that the improved safety and self-reported confidence associated with stance MPC (i.e., EESs 6-A and 6-C) may allow users to walk more rapidly.

The measurement of temporal, spatial, kinetic, and kinematic symmetry among individuals with unilateral TFLL is a common scientific and clinical pursuit. These efforts are likely related to the goal of better understanding and addressing the documented asymmetry in gait parameters in this population $[4,36-37,115,117,152-153]$ and the elevated incidence of lower-back pain $[16,154$ $155]$, joint pain $[16,155]$, and osteoarthritis $[16,18,155-$ 156] that these asymmetries are believed to cause. Prosthetic interventions such as MPKs are often evaluated for their potential to reduce asymmetry and, presumably, to affect these degenerative changes. Neither swing-only nor swing and stance MPKs were found to significantly change spatial symmetry (i.e., step length) compared with NMPKs (EESs 4-C and 4-D). One explanation may be that spatial asymmetries are most often caused by issues that are addressed by the prosthetist while the subject walks at SSWS in the clinic. Thus, significant differences in symmetry as a result of changing prosthetic knees may appear at faster or slower walking speeds, as noted by Jepson et al. [77] and Kirker et al. [80] for swing and stance and swing-only MPKs, respectively.

Temporal symmetry (i.e., percent stance time) was not often explored, and studies reported conflicting results related to changes produced as the result of swing and stance MPK use (EES 4-E). Jepson et al. [77] reported no change in stance time between swing and stance MPKs and NMPKs, while Johansson et al. [78] reported a significantly increased step time on the prosthetic side, with one (RHEO KNEE) of the two MPK models studied [78]. Although this finding is interesting, further investigation will be required to determine whether this specific type of MPK has the potential to address temporal asymmetries. Two studies $[76,99]$ that examined temporal symmetry between swing-only MPKs and NMPKs showed no significant differences between the prosthetic knees at SSWS [76] and CWS [99], suggesting that swing-only prosthetic knees do not greatly affect temporal symmetry.

The influence of MP technology on gait kinematics has received relatively little attention in the reviewed body of literature. The sole EES generated in this review on this topic indicated that peak stance-phase knee flexion was equivalent between swing and stance MPKs and NMPKs (EES 4-F). An increase in flexion was expected, because some models of MPKs are believed to possess so-called "stance flexion," which presumably would allow the prosthetic knee to flex slightly during loading response. This EES (EES 4-F) was not well supported by the literature because the results varied between studies. While Kaufman et al. [97] reported significantly increased knee flexion with a swing and stance MPK compared with an NMPK, Segal et al. [98] reported no significant difference for the same comparison. A pilot study by Herr and Wilkenfeld also noted an increase in early stance flexion with the MPK but did not conduct a statistical analysis [96]. Given these conflicting results, more research is needed to draw a definitive conclusion. One potential reason that the early flexion was not measured across all the studies may be because of the alignment of the MPK. Willingham et al. suggested that MPKs may be aligned following traditional methods with the GRF too anterior to the knee-joint center, thus limiting 
their ability to achieve this stance flexion [157]. Additional research would be needed to explore this hypothesis. Individual studies showed significant changes in peak swingphase knee-flexion angle [98] and stance-phase hip angle [78] on the prosthetic limb while using swing and stance MPKs, but corroborative studies would be required to formulate EESs based on these findings.

As with joint kinematics, joint kinetics were infrequently studied across the reviewed literature. The limited kinetic evidence suggests that, in most respects, MPKs and NMPKs performed similarly. However, swing and stance MPKs were reported to significantly increase the knee-flexion moment (EES 4-G), perhaps as a result of the induced knee flexion noted in several of the studies discussed previously. Alternatively, the increased moment in this phase of gait may be due to the more anterior alignment recommended for this type of MPK compared with the traditional alignment of NMPKs. Although prosthetic hip power during late stance was found to be equivalent between knees (EES 4-H), inconsistency in the results suggests that more research is needed to strengthen the EES. While it may be expected that a more accommodating prosthetic knee might be easier to flex in late stance, reducing the need for hip flexion to enter swing phase, users with a short accommodation period showed a significant reduction in hip power with the MPK [78]. Users with 3 mo of experience did not show a significant difference in hip power between prosthetic knees, suggesting that accommodation to the knee may mitigate changes in hip power in late stance [98].

Interestingly, time since amputation and experience with the interventions varied greatly among gait mechanics studies (Table 3). Variations in these personal factors may affect the extent to which the subjects could learn to use and/or trust the MPK or to adopt a revised gait pattern. Similarly, the training provided to subjects was not commonly discussed. Training has been reported to have immediate and lasting effects on gait mechanics and may therefore influence outcomes when provided in conjunction with a prosthetic intervention [158]. More research is needed to understand the interaction and potential benefits of providing prosthetic interventions with physical therapy.

Evaluating gait mechanics publications also identified several methodological issues that may influence the presented outcomes. Traditional instrumented gait analysis relies on the use of a preselected link-segment model and associated biomechanical assumptions to establish the three- dimensional position of the body segments in space. The development of traditional models for ambulation and the underlying assumptions are historically based on nondisabled individuals and may not accurately reflect the physiology and function of individuals with lower-limb prostheses [159]. Specifically, definition of the body-segment parameters and position of the joint-center locations may differ between nondisabled individuals and individuals with LLL. Of those publications included in this review, Johansson et al. addressed differences in mass and mass distribution between the prosthetic and nondisabled limbs [78]. Similarly, Segal et al. [98] and Johansson et al. [78] provided descriptions of the biomechanical models used to conduct their respective analyses. However, neither described the process for identifying or defining the joint centers. Because the estimation of kinetics is sensitive to the location of the joint centers, this may have influenced the resultant outcomes. Details regarding these decisions may help readers better understand the assumptions made by the investigators and place the results in the proper context.

As with many of the aforementioned metabolic energy expenditure studies, the large majority of gait mechanics experiments have been performed under strictly controlled laboratory conditions. Given the sophisticated equipment needed for performing full-body motion analysis, it is not surprising that these laboratories have been, and continue to be, used to collect such outcomes. Laboratory settings allow investigators to control confounding variables and improve the quality of the scientific experiments. However, most laboratories consist of flat, level terrain that may not represent a user's free-living environment. The results gathered from testing in such environments may not generalize well to real world situations. The few differences between MPKs and NMPKs related to gait mechanics may be due to the environment in which they are measured. Alternative means for acquiring temporal, spatial, kinematic, and kinetic data may offer the means to assess this possibility. Portable systems that consist of sensors for tracking body movement in the free-living environment are now available and may be used to collect gait mechanics outcomes [160-161]. The use of such systems in conjunction with traditional laboratory-based equipment may allow for the assessment of function as well as activity and/or participation [162], enhancing our understanding of how prosthetic interventions are used across a variety of environmental conditions.

The alignment of prosthetic components has also received relatively little attention in the reviewed body of 
literature. Traditionally, definitive prosthetic alignment is derived from component manufacturers' recommendations and an iterative process of subjective patient feedback and observational gait analysis. Although Blumentritt et al. reported that a range of acceptable transfemoral alignments exists [163], the influence of alignment on clinical and/or scientific outcomes has rarely been studied [82,164] and is not well understood. Kaufman et al. suggested that variations in MPK gait mechanics may vary across the body of literature because of differences in prosthetic alignment [97]. While plausible, insufficient detail regarding a subject's alignment is typically provided in individual studies to support or refute this hypothesis. In the future, improved standards for documenting and reporting prosthetic-limb alignment may allow readers to better assess the influence of alignment on the study outcomes. While several publications have described the use of tools that have been developed to aid in the quantification of lower-limb prosthetic alignment [82,102,157,165-166], their regular integration into comparative research protocols or publications has yet to occur.

\section{Environmental Obstacle Negotiation}

Negotiating environmental obstacles and nonlevel terrain (i.e., curbs, ramps, steps) is commonly recognized as a requisite component of functional independence and community participation [167-168]. The potential to traverse such barriers is noted as an important mobility differentiator that transitions individuals with LLL from MFCL-1 ("limited and unlimited household ambulator") to MFCL-2 ("limited community ambulator") [169], a designation that provides them with access to additional prosthetic options under many medical insurance programs. Users also perceive a need to traverse such conditions. Legro et al. reported that lower-limb prosthesis users rated the ability to negotiate sidewalks, streets, and stairs as "highly important" ( $>90$ on a 100-point scale) [50]. The ability to walk on slippery surfaces and hills was noted to be of lesser, yet modest ( $\geq 60$ on a 100-point scale), importance. However, engaging in such activities while using a prosthesis is often challenging. Research has shown that negotiating nonlevel terrain requires greater muscle activity [170-171], produces altered gait patterns $[23,44,172]$, and induces greater loads on the nondisabled limb [172] in individuals with TFLL. Given these challenges, the extent to which prosthetic interventions such as MPKs may address these restrictions is of particular scientific and clinical interest.
The evidence derived from this review revealed that the negotiation of uneven terrain by individuals with TFLL is significantly improved with the use of swing and stance MPKs than NMPKs (EES 5-A). Despite slight differences in the obstacle courses used across the reviewed studies, each offered a variety of challenging terrains (i.e., grass, rocks, sand, wood chips) commonly encountered by community-ambulating individuals. Three publications reported a significant decrease in the time needed to complete the obstacle course when using the swing and stance MPK than when using the NMPK $[72,83,90]$, while a fourth reported a nonsignificant decrease in time associated with the task [73]. This course used by Hafner and Smith [72] and Hafner et al. [73] included additional environmental barriers (i.e., a ramp and descending stairs) that were not included in the other studies $[83,90]$, which may have influenced the results. Interestingly, subjects initially rated as MFCL-2 in one study [72] showed nearly twice the improvement in obstacle course time than those rated MFCL-3. This may again suggest that knee MPC has the potential to address functional deficits differently across MFCL groups and should be explored further.

The ability to negotiate uneven terrain with swingonly MPKs was reported in a single cross-sectional study [88] and therefore did not contribute to an independent EES. However, subjective reports of users in this study found that many (14 of 21) perceived an improved ability to ambulate over uneven roads. This result is somewhat surprising, given that the ability to safely and efficiently negotiate uneven terrain would seem to depend more on stance-phase stability than swing-phase agility. While a swing-only MPK is purported to provide improved swingphase response over a wider range of cadences, it is not believed to provide additional stance-phase stability that would aid in improving negotiation of environmental barriers. It is possible that the swing-phase MPC ensured that the foot was better positioned for initial contact and as a result was perceived to be more secure. At this time, the ability of swing-only MPKs to influence ambulation on uneven terrain should be considered preliminary until further corroborative work can be provided. This does, however, illustrate a need for additional research to determine more accurately whether negotiating uneven terrain is a feature of swing-phase agility, stance-phase stability, or a combination of the two.

Legro et al. reported that the ability to descend stairs is perceived by prosthesis users to be of high importance 
[50]. However, in MacKenzie et al., as few as 43.5 percent of those individuals with TFLL describe being able to independently perform this activity [173]. Evidence obtained through this review suggests that the use of swing and stance MPKs results in significantly improved stair descent compared with the use of NMPKs (EES 5B). The contributing studies [72-73,90] used standardized [100] and ad hoc [100,174-175] observational outcome measures to describe the gait patterns of the study subjects as they descended stairs. Note that the psychometric properties of these measures have not yet been well established in this population. For example, Kahle et al. [90] selected the MRPP, a measure designed for children with developmental disabilities [100], while Hafner and Smith [72] and Hafner et al. [73] used the SAI [174], a novel instrument developed for individuals with LLL. However, because no other means to assess stair function have been validated with individuals with LLL, an area of future work may be to validate these or other measures of stair negotiation for use in this population. Interestingly, Jepson et al. reported that three of five subjects perceived greater challenges walking down stairs with a swing and stance MPK than with their prior NMPK [77]. Notably, several subjects in this study did not fully attend the physiotherapy program offered with the MPK. Though not explicitly stated, the program may have addressed skills needed for successful stair descent and may thus have been a reason that the users felt challenged descending stairs.

Hill descent, in contrast to stair descent, has received relatively little attention in this body of literature. Hafner and Smith [72] and Hafner et al. [73] examined the influence of MPK use on this activity. Results from these publications suggest that use of a swing and stance MPK significantly improves the speed [72-73] and pattern [72] of hill descent, but confirmatory work is needed to substantiate the EES. Buell et al. used a novel measure of stepping pattern, the HAI [175], to quantify descent pattern. As noted previously for measures of stair function, a need exists to validate and/or develop improved measures of hill function for this population.

The reported improvements in hill and stair descent with the use of a swing and stance MPK are likely due to the stance-phase features present in this type of knee joint. The stance-resistance behavior in stance-control MPKs [62] may mimic the eccentric contractions of the extensor muscles in a nondisabled knee and play a dominant role in progressing from one step to the next during stair descent
[176]. Conversely, this feature does not appear to influence a user's ability to ascend hills or stairs [73]. Because individuals with nondisabled physiology accomplish ascent patterns primarily through concentric power generating contractions of the knee extensor muscles, this finding is not unexpected. Active or powered extension of the knee joint is not provided by the MPKs that have been evaluated in the reviewed peer-reviewed literature to date, but this feature is present in at least one commercially available prosthetic knee (POWER KNEE, Össur Americas) at the time of this publication. Given the potential for prosthetic knees of this kind to promote stair ascent, investigators may consider including stair ascent as an outcome of interest in future studies.

Because knee-stability features are likely responsible for a user's ability to descend stairs and hills, it is not surprising to find a scarcity of literature describing the influence of swing-only MPKs on hill and/or stair descent. In a survey of swing-only MPK users, Datta and Howitt reported that 5 of 22 subjects perceived an improved ability to descend stairs [88]. Interestingly, a larger portion of the respondents (13 of 22) reported an improved ability to negotiate slopes and hills when using the swing-only MPK [88]. Such findings are of interest because the descent of hills and stairs would not seem to be affected by swing-phase MPC. As noted previously, it may be possible that the MP aids in better positioning the prosthetic foot for initial contact on nonlevel terrain. However, additional research would be needed to explore this possibility or explain why users perceive a benefit when using swing-only MPKs.

Given the clinical perception that MPKs are prescribed for relatively active individuals and that they promote community ambulation, it may be surprising that the ability to negotiate environmental obstacles and nonlevel terrain has not received more attention. The relative paucity of research in this area may stem from a lack of suitable resources for measuring functional ability related to the aforementioned activities. Although traditional biomechanists may have access to motion analysis laboratories, few may have the space to establish obstacle courses or include stairs and inclines within the available capture volume. Perhaps with the advancement of portable instrumentation systems [160-161], evaluation of environmental barriers in a user's natural environment may be possible. As an alternative, investigators may consider incorporating less sophisticated measures of environmental obstacle negotiation, such as timed stair 


\section{SAWERS and HAFNER. Systematic review of microprocessor-controlled prosthetic knee use}

tests [177] or standardized obstacle courses [178-179], into study protocols as a way to measure these activities.

Safety

Individuals with LLL commonly present with compromised balance [4,24], which is further exacerbated by a limited ability to cope with balance perturbations using the prosthetic limb [180]. These issues likely contribute to the reported increased incidence of falls and stumbles $[27,181]$, decreased balance confidence [26,39], and fear of falling [27] in this population. Notably, $>60$ percent of individuals with TFLL have reported at least one fall in the past month [181] or year [27] in retrospective surveys. Not unexpectedly, Legro et al. reported that feeling balanced when using a prosthesis has been rated as highly important among these individuals [50]. Thus, any intervention that addresses some or all of these issues may be considered to be clinically relevant.

Although ambulatory safety is considered an important clinical issue, the effect of MP technology on safety outcomes has rarely been studied in the body of literature. The paucity of research in this area may be because of historical prescription paradigms that associate advanced prosthetic technology, like MPKs, with functional performance needs (i.e., ambulation variable cadence) rather than enhanced safety features. For example, patients who are currently considered candidates for MPK technology (i.e., MFCL-3 or MFCL-4) are generally not thought to be at the greatest risk for falls than typically less active and stable MFCL-2 patients. However, those MFCL-2 patients who may be at the greatest risk for falls are not currently deemed candidates for MPKs.

Results of this systematic review indicate that, when compared with NMPKs, swing and stance MPKs significantly decrease the number of subject-reported stumbles and falls (EES 6-A), while reducing frustration with falls (EES 6-B) and increasing balance confidence (EES 6-C). Remarkably, Kahle et al. noted the frequency of falls decreased by as much as 64 percent with use of the MPKs [90]. For individuals rated as MFCL-2, Hafner and Smith noted an even more impressive 80 percent decrease [72]. Mechanistic studies of individuals' biomechanical responses to physical perturbations while wearing both swing and stance MPKs and NMPKs similarly show improvements in standing [97] and walking [102] balance while using MPKs. From a clinical perspective, this evidence may have important long-term health implications. The potential for an intervention to mitigate falls, the subsequent injuries, and the associated medical costs (or productivity losses) seems intriguing and may lend itself to future scientific explorations.

A noted limitation of those studies that examined subject-reported falls and stumbles [72-73,77,90] was the use of retrospective, rather than prospective, user reports. Retrospective reports are generally believed to be as specific but less sensitive than prospective data collection methods that use a calendar or diary [182]. Recent reviews have recommended that falls should be recorded using prospective recording systems [183] with a weekly or monthly recall period [182] in order to avoid forgetting events or including events outside of the desired time frame. Prospective studies related to the frequency of adverse events such as stumbles and falls may therefore be a priority for future research. Similarly, exploring the means to objectively measure adverse events may be beneficial [184-186].

Based on these findings, patient candidacy is an area of research that logically warrants further exploration. As previously noted, the prescription of MPKs has been historically reserved for patients who are capable of achieving variable cadence (i.e., MFCL-3). This is likely because of manufacturers', clinicians', and reimbursement agencies' original focus on those characteristics of the MPK that addressed the needs of the active user (i.e., walking faster, minimizing metabolic energy expenditure). However, an increasing body of evidence related to stability features (and associated safety outcomes) in recent years demonstrates the potential for MP technology to benefit less active and less stable patients. In light of the existing evidence, it seems prudent to consider that prescribing MPKs should not be limited to those patients for whom variable cadence is possible but extended to those patients who demonstrate challenges with stability [187].

\section{Preference and Satisfaction}

Physiological or biomechanical responses to interventions do not necessarily translate into those outcomes most desired or deemed important by individuals with LLL. The role of patient preference and/or satisfaction has long guided decisions in the provision of prosthetic care, but only recently has it begun to receive attention in the prosthetic literature [188]. Although populationbased surveys of overall use and satisfaction with prostheses (and/or prosthetic services) among individuals with LLL exist [181,189-192], none of these describe 
how preference or satisfaction is influenced by specific prosthetic components.

This systematic review revealed that, as a group, users preferred both swing and stance MPKs (EES 7-A) and swing-only MPKs (EES 7-B) to NMPKs. While subject groups included in the reviewed studies often indicated an overall preference for the swing and stance MPK, this was not a universal outcome because there were individuals who preferred the NMPK prosthesis. Interestingly, preference was not always correlated with performance. In several instances, outcomes were noted to improve with use of the MPK, yet those subjects still preferred the NMPK [90]. This again raises interesting and important questions regarding component candidacy and prescription criteria for MPKs. While user choice has been identified as an important factor when matching prosthetic technology to the patient [193], further investigation into component preferences among individuals with TFLL is warranted to better understand the social, physical, and psychological characteristics associated with prosthetic knee preferences. Notably, patient characteristics such as time since amputation, previous prosthesis experience, and activity level may all be factors that influence prosthetic knee preference. Likewise, additional research is needed to determine which characteristics of the prosthetic knee (i.e., performance, weight, cosmesis) drive or motivate user preference. This latter topic was briefly addressed by Orendurff et al., who noted that several subjects in their study offered unsolicited preference for the swing and stance MPK over a stance hydraulic prosthetic knee because of perceptions that the MPK resisted stumbles and accommodated to any walking speed they chose [81]. Interestingly, these comments appear to corroborate two EESs (4-A and 6-A) generated within this systematic review.

In addition to increased preference, the use of swing and stance MPKs also appears to be associated with improved patient satisfaction when compared with the use of NMPKs among individuals with unilateral TFLL (EES 7-C). The contributing studies all measured satisfaction with the first question on the PEQ, which states, Over the past $4 \mathrm{wk}$, rate how happy you have been with your current prosthesis? Although this question is directed at user satisfaction, it is not validated as a stand-alone item of the PEQ [50] and therefore may not reflect the desired construct. Additional psychometric development would be required to confirm that this question is a stand-alone measure of satisfaction. Interestingly, many studies that describe the satisfaction of prosthesis users elect to use ad hoc outcome measures. One reason may be the relative lack of validated instruments to assess satisfaction in this population. The Orthotic and Prosthetic Users' Survey is one population-specific measure that has undergone both reliability and validity testing as part of its psychometric development [194]. Other measures, such as the Satisfaction with a Prosthesis [195], Trinity Amputation and Prosthesis Experience Scales [196], Orthotic and Prosthetic Outcomes Tool [197], and Attitude to Artificial Limbs Questionnaire [198], have received preliminary testing in the literature and may yet require additional validation before they can be universally recommended. However, future studies may consider continued psychometric development of these measures and/or inclusion of such measures in intervention studies if satisfaction is deemed to be a construct of importance.

One concern related to preference includes the user's expectations or the associated potential for bias. Notably, MPKs have received considerable attention in the general [199] and consumer [200] literature. It is therefore likely that some or all of the subjects in the reviewed studies may have received some exposure to the intervention(s) prior to their participation. Given that blinding was not used in any of the studies relevant to this outcome topic, the reported preference for the MPKs may have been related to the novelty of the intervention. As noted previously, we acknowledge the challenges with blinding such interventions. However, without further assessment of the factors that influence prosthetic knee preference, a strong and unbiased link between MPKs and user satisfaction cannot be established. The relationships between patient preference, opinions on new or emerging technology, and clinical outcomes also remain largely unexplored within lower-limb prosthetics but are likely to be a critical factor in understanding and establishing positive PROs [193]. Given these considerations, it may be important for future outcome measures to address issues of satisfaction by incorporating the concept of patient expectation.

\section{Economics}

Growing healthcare costs have prompted changes in the way interventions are examined and provided. As a result, researchers, clinicians, and policy makers are increasingly aware of a growing need for economic analyses that evaluate intervention outcomes in context with the costs required to provide them. The reviewed body of literature included several types of economic analyses, including cost utility 
analyses and cost consequence analyses [201]. In these analyses, cost may include acquisition costs, healthcare costs, and/or other societal costs (e.g., housing modifications, personal care assistance, productivity losses). Similarly, utility pertains to the consequences of the intervention, including both the QOL and quantity of life gained through its provision. It is typically expressed as a QALY. Although the means for acquiring this information and scope of included information vary among the reviewed studies, the goal of each was to examine and weigh the differences in costs, utility, and cost-utility ratios for the compared interventions. We examined costs associated with the prosthetic knees from several perspectives in this review. First, we found the initial MPK acquisition costs to be significantly greater than the NMPK (EES 9-A). While readers may likely accept this information without the derived EES, recall that the purpose of this review was to generate empirical evidence based on the significant findings reported in the peer-reviewed literature. Here, the economic studies $[89,92,105]$ elected to measure and compare the initial cost of the interventions, thus providing the information needed to derive the EES. While not unexpected, EES 9-A becomes more interesting when contrasted against the broader societal costs (EES 9-B).

It has been recommended that economic analyses be performed from a societal perspective to best represent the public interest over that of any specific group (e.g., reimbursement agencies or patient groups) [202]. Two of the reviewed studies approached costs in this manner and included analysis of expenses beyond the prosthetic prescription, including medical visits, pharmaceutical prescriptions, hospitalizations, transportation, home modifications, housekeeping assistance, and productivity losses [89,92]. For example, Gerzeli et al. reported mean intervention costs of $€ 18,616(\$ 22,348)$ and $€ 3,600(\$ 4,328)$ for the MPK and NMPK prostheses, respectively [89]. However, after considering all societal costs related to intervention maintenance, medical services, transportation, caregiving, and productivity losses for the 50 subjects enrolled in each group in the study, mean costs were $€ 66,669(\$ 80,162)$ and $€ 66,927$ (\$80,473), respectively. The largest societal cost differences in the reviewed literature were attributed to the category of productivity losses. Both Gerzeli et al. [89] and Seelen et al. [92] noted larger productivity losses with NMPK users than MPK users, suggesting that the MPK may be more effective at allowing users to return to work. Thus, the available evidence indicated that total costs for prosthetic rehabilitation from a societal perspective were equivalent between swing and stance MPKs and NMPKs (EES 9-B).

The reviewed economic analyses ultimately reported the required cost to gain an additional QALY through the prescription and use of a swing and stance MPK compared with an NMPK. The incremental cost per QALY varied from $€ 3,218(\$ 4,132)[105]$ to $€ 35,971(\$ 43,251)$ [89] when considering only prosthesis cost. The difference in these incremental costs per QALY may be attributed to the greater cost of the NMPK prosthesis and/or the greater QALY associated with the MPK prosthesis described by Brodtkorb et al. [105]. However, when including societal costs, there is a reported cost savings of $€ 614$ (\$738) per QALY with the prescription and use of a swing and stance MPK [89]. In an effort to interpret these numbers, benchmarks have been proposed to establish a reasonable cost per QALY. Established values appear to range between $\$ 30,000$ and $\$ 100,000$ [203]. Based on this evidence, it would appear that the prescription and use of swing and stance MPKs might be considered a cost-effective technology and, despite initially being more expensive, would appear to be an effective alternative for reestablishing a life that is both of higher QOL and longer duration.

Note that the data provided through economic analyses may be interpreted differently by different decision makers. The reviewed studies $[89,92,105]$ were all conducted within countries with nationalized healthcare systems. In such cases, the societal costs may be of specific interest to national agencies from a financial perspective. Conversely, many individuals with LLL in the United States subscribe to private medical insurance programs. These private reimbursement companies may not weigh societal costs in the same manner as a national agency. In such cases, the initial acquisition costs may be prioritized and may therefore be favored in conducting future cost utility analyses. One means of addressing this potential challenge is to report both acquisition and societal costs, as done by Gerzeli et al. [89]. Incremental costs may then be calculated from either perspective.

\section{Health and Quality of Life}

QOL has become an increasingly popular concept in the assessment of outcomes. Though challenging to define, QOL often relates to the subjective elements that contribute to an individual's happiness and satisfaction with life. This broad concept has historically included such elements as health, education, family life, vocational 
experiences, and financial status. The term HRQL, often used interchangeably with general health status [204], reflects those QOL elements that influence (or are influenced by) health. HRQL has been noted to describe the physical, mental, social, and emotional aspects of health and may include personal relationships, functional ability, pain, perceptions of self and others, satisfaction with life, and well-being [138,205]. As may be expected, selfreported HRQL varies greatly among individuals with LLL [138,206-207]. Contributing factors are not well understood, although a study by Asano et al. suggested that depression, prosthetic mobility, and social support are those factors most likely to predict HRQL in this population [206]. Comparisons of HRQL between individuals with LLL and nondisabled individuals are rare [48-49], but those that exist have reported several key significant differences. Hagberg and Brånemark [49] reported a significantly decreased overall $\mathrm{HRQL}$, as measured by all eight dimensions of the SF-36 [52], among 97 individuals with nondysvascular unilateral TFLL when compared with those of age- and sex-matched persons. Similarly, Dougherty found that 46 Vietnam war veterans with TFLL reported significantly lower SF-36 physical function and general health subscale scores than that of ageand sex-matched controls [48]. Given the reported reduced QOL in this population, HRQL measures are often included in studies of interventions that are believed to influence general health. The QALY, a calculated preference for a health state (i.e., weighted on a scale from 0 [dead] to 1 [optimal health]), multiplied by the time (years) spent in that health state, is the recommended outcome for economic analyses [202] because intermediate outcomes such as metabolic energy expenditure, gait speed, and cognitive demand may not well reflect the broad concepts of health and well-being. The evidence identified in this systematic review indicated that the use of swing and stance MPKs results in a significantly greater number of QALYs than the use of NMPKs (EES $8-C)$. In both cases, the preference for the health state was determined by using the study subject's (i.e., prosthesis user's) EuroQol EQ-5D scores [106]. Note that one of these studies used a within-subjects design that required MPK users to reflect back on their prior experience with the NMPK, perhaps biasing the results of the subjective data to the current intervention (i.e., the MPK) [105]. Notably, the QALY difference reported in this study (2.98) was substantially larger than that $(0.42)$ obtained by Gerzeli et al. [89], who used a larger group design. Thus, additional prospective research may be needed to confirm the incremental QALY provided by an MPK compared with an NMPK.

Interestingly, the evidence derived from this systematic review indicates that using a swing and stance MPK, compared with an NMPK, results in an equivalent level of general health (ESS 8-A) and significantly increased level of well-being (EES 8-B). While both EESs address one of the aforementioned subdomains of HRQL, the discrepancy between them may be the result of the items contained within the selected outcome measures. General health, as described by EES 8-A, was measured by all contributing studies using the SF-36 [52]. SF-36 general health subscale questions poll the respondent about his or her overall health, specifically addressing such aspects as "getting sick." Thus, these questions may not draw attention to health related to LLL or prosthesis use. Many individuals with LLL also experience comorbidities that may limit their perception of physical functioning with respect to their general health. Alternatively, well-being (EES 8-B) was measured exclusively using the PEQ well-being subscale [208]. The PEQ is a population-specific measure designed to solicit information regarding use of the prosthesis. PEQ well-being subscale questions relate to a respondent's satisfaction with how well things have "worked out since [the] amputation" and will likely draw the respondent's attention to his or her condition and the prosthesis. Hence, if an MPK does indeed improve QOL, it should not be surprising that the PEQ is more sensitive than the SF-36 to the changes produced by this intervention.

Clearly, measuring HRQL is a challenge. Selecting and using a generic outcome measure allows for comparisons to normative values in nondisabled (or other related) populations. However, generic HRQL measures may not be as sensitive to issues of concern in the population of interest. Population- or condition-specific measures are likely to be more specific and sensitive but may not allow for comparisons between individuals with different conditions because normative data may not exist [209]. One potential solution is the inclusion of both types of measures in a study, an alternative not often selected in the reviewed studies. Measuring health in the population of individuals with LLL also presents several unique challenges. In addition to issues of physical function, this population also experiences pain [136], depression [206], lowered energy [136-137], and sleeplessness [137], all of which can affect overall health. Many of these are condition-related, and thus, may respond to changes in prosthetic 
interventions and may be considered in future outcome studies.

Lastly, individual expectations with rehabilitation may also have the potential to influence HRQL. Although the connection between expectations and HRQL remains largely unexplored [210], clinical experience suggests that outcomes are often affected by the patient's perceptions of rehabilitation. Methodological approaches to developing expectations, setting goals, and individualizing treatment, such as the Patient Generated Index [211] and Goal Attainment Scaling [212], have been used to assess the preferences of individual prosthesis users but not in conjunction with an interventional trial. They may be of benefit in exploring the changes in QOL associated with specific prosthetic interventions such as those reviewed here.

\section{Limitations of Review}

This work is not without limitations. We intended the question developed to guide this systematic review to address the most common clinical population, individuals with unilateral TFLL, in which MPKs are prescribed and used. By definition, this excluded individuals with bilateral TFLL and those with more proximal levels of LLL for which the use of MPKs may be appropriate. While we excluded studies pertaining to the use of MPKs among these populations from the formal review process and the creation of the EESs, we considered and included them within the discussion as appropriate.

The prosthetic knee technologies discussed in this review (i.e., swing and stance MPKs, swing-only MPKs, and NMPKs) represent categories of components. Subtle differences in behavior among specific models (e.g., Compact C-Leg and RHEO KNEE) and outcomes achieved with their use are not well understood. Thus, while we have generalized the EESs developed in this review to the specific type of prosthetic knee (i.e., swing and stance or swing-only), readers are cautioned to note that the published literature reflects a small subset of those prosthetic knees that are commercially available and it is derived predominantly from outcomes related to two specific models (i.e., Compact C-Leg and SmartIP). Because most commercially available MPKs have yet to be the focus of scientific study, outcomes related to their use may be loosely extrapolated based on functional similarities to those prosthetic knees that have been studied. A detailed comparison of the functional similarities and differences among different models is beyond the scope of this review, so readers must use their own clinical judgment when extrapolating the evidence presented here in relation to other MPKs.

This systematic review may be limited because it includes publications up to October 2009. In the interim period between the literature search and final submission of this review for publication, additional studies pertinent to the topic of this review were published [213-216]. Readers are encouraged to consider these publications in light of the findings presented here.

Another perceived limitation of this review may be the potential for bias by one of the review authors (B. H.), who also coauthored two publications included in this review. To address this potential bias, an alternate reviewer scored these publications rather than the study author. Similarly, we believe that the use of a systematic review process and standardized quality assessment mitigated this potential bias.

The described review process [71] and its associated classification and rating systems may likewise be perceived to be a limitation of the review because they have received little attention in the literature. The AAOP developed the guidelines for review used here to evaluate O\&P literature and subsequently to create evidence reports on relevant O\&P healthcare topics. Although this system is relatively new, note that no universally accepted system exists to rate methodological quality [217]. Furthermore, these guidelines have successfully been used in other systematic reviews of O\&P interventions [74,109-110]. We acknowledge that additional work may be required to evaluate the reliability of this review process, to assess the effect of weighting IV and EV criterion, and to compare the outcomes generated here to other standardized reviews, such as those established by the Cochrane Collaboration [218].

Lastly, an ideal EBP approach to clinical decisionmaking recognizes that multiple sources of information exist and each should be appropriately considered when formulating and rendering a decision. Sources of knowledge that have been identified as valuable components to EBP include empirical evidence, experiential evidence, pathophysiologic rationale, patient values and preferences, and system features (i.e., facilitators of care) [219]. The relative importance of each of these areas must be considered and then weighed in the context of the individual patient in order to arrive at the best clinical decision [219-220]. The extent to which each of these sources of evidence is used in making a clinical decision is beyond the scope of this review but clearly depends on 
which sources are available. The findings of this systematic review represent a comprehensive source of empirical evidence, one that has been derived from a wide variety of peer-reviewed, published research studies. It should be acknowledged that the most effective use of these findings will not occur in isolation but rather when appropriately integrated with the other sources of information and knowledge that contribute to effective EBP.

\section{CONCLUSIONS}

We reviewed the body of scientific, peer-reviewed literature in an effort to identify changes in outcomes associated with the prescription, fit, and use of MPKs when compared with NMPKs among individuals with unilateral TFLL. We identified nine outcome topics (metabolic energy expenditure, activity, cognitive demand, gait mechanics, environmental obstacle negotiation, safety, preference and satisfaction, economics, and health and QOL) and generated EESs related to each topic. Varying levels of evidence exist to indicate that the prescription, fit, and use of swing and stance MPK lead to changes in outcomes for individuals with unilateral TFLL when compared with NMPKs.

Moderate evidence exists to suggest that swing and stance MPKs are associated with increased confidence during ambulation, increased self-reported mobility, reduced self-reported cognitive demand while walking, improved self-reported well-being, and equivalent overall societal costs when compared with NMPKs. Low evidence indicates that these MPKs are also associated with increased walking speed on uneven terrain, improved gait patterns in stair descent, decreased numbers of falls, greater user satisfaction, greater user preference, decreased rate of $\mathrm{O}_{2}$ consumption while walking at SSWS, increased SSWS, and increased knee moment in early stance. Moderate to low evidence suggests that swing and stance MPKs and NMPKs result in similar levels of activity, cognitive burden while walking, self-reported general health, rate of $\mathrm{O}_{2}$ consumption at SSWS, $\mathrm{O}_{2}$ cost over a range of walking speeds, and spatial symmetry. Insufficient evidence exists to assess the effect of swing and stance MPKs on temporal symmetry, peak knee-flexion angle, and prosthetic-side hip power. Low evidence suggests that swing-only MPKs are associated with increased user-reported preference compared with NMPKs. Moderate to low evidence indicates that swing-only MPKs produce similar rates of $\mathrm{O}_{2}$ consumption while walking, cognitive burden while walking, SSWS, and spatial symmetry to NMPKs. No evidence suggests that NMPKs provide improved clinical outcomes when compared with MPKs within this body of literature.

This article represents the most comprehensive and detailed collection of evidence regarding the influence of MPKs on the rehabilitation of individuals with unilateral TFLL. Given the current level of empirical evidence, we can conclude that MPKs are indicated for those individuals who require an increase in safety or an improved ability to descend stairs and/or negotiate uneven terrain. The provision of an MPK is also likely to be met with improved patient preference and satisfaction, an improved perception of mobility, and a reduced perception of the effort required for ambulation. Further, MPKs appear to offer these benefits at equivalent total prosthetic rehabilitation costs compared with traditional alternatives. Based on the available evidence, MPKs do not appear to influence outcomes related to $\mathrm{O}_{2}$ consumption, physiological measures of cognitive demand, or the amount of daily activity performed. These findings may be used to indicate those individuals with unilateral TFLL for whom this prosthetic knee technology is most appropriate.

\section{ACKNOWLEDGMENTS}

\section{Author Contributions:}

Study concept and design: A. B. Sawers, B. J. Hafner.

Drafting of manuscript: A. B. Sawers, B. J. Hafner.

Critical revision of manuscript for important intellectual content:

A. B. Sawers, B. J. Hafner.

Financial Disclosures: The authors have declared that no competing interests exist.

Funding/Support: This material was based on work supported by a Center of Excellence grant (A4883C) from the Department of Veterans Affairs Rehabilitation Research and Development Service and a Department of Education grant (H235J060001) to the AAOP.

Additional Contributions: The authors would like to thank Danny Abrahamson for acting as an alternate reviewer and participating in the assessment of the methodological quality for two of the included studies. Dr. Sawers is now with the Wallace H. Coulter Department of Biomedical Engineering, Emory University and the Georgia Institute of Technology, Atlanta, Georgia.

\section{REFERENCES}

1. Ziegler-Graham K, MacKenzie EJ, Ephraim PL, Travison TG, Brookmeyer R. Estimating the prevalence of limb loss in the United States: 2005 to 2050. Arch Phys Med 
Rehabil. 2008;89(3):422-29. [PMID:18295618]

http://dx.doi.org/10.1016/j.apmr.2007.11.005

2. Dillingham TR, Pezzin LE, MacKenzie EJ. Limb amputation and limb deficiency: epidemiology and recent trends in the United States. South Med J. 2002;95(8):875-83. [PMID:12190225]

3. Adams PF, Hendershot GE, Marano MA; Centers for Disease Control and Prevention/National Center for Health Statistics. Current estimates from the National Health Interview Survey, 1996. Vital Health Stat 10. 1999;(200): 1-203. [PMID:15782448]

4. van Velzen JM, van Bennekom CA, Polomski W, Slootman JR, van der Woude LH, Houdijk H. Physical capacity and walking ability after lower limb amputation: a systematic review. Clin Rehabil. 2006;20(11):999-1016.

[PMID:17065543]

http://dx.doi.org/10.1177/0269215506070700

5. Schoppen T, Boonstra A, Groothoff JW, de Vries J, Göeken LN, Eisma WH. Physical, mental, and social predictors of functional outcome in unilateral lower-limb amputees. Arch Phys Med Rehabil. 2003;84(6):803-11. [PMID:12808530] http://dx.doi.org/10.1016/S0003-9993(02)04952-3

6. Pohjolainen T, Alaranta H, Kärkkäinen M. Prosthetic use and functional and social outcome following major lower limb amputation. Prosthet Orthot Int. 1990;14(2):75-79. [PMID:2235304]

7. McWhinnie DL, Gordon AC, Collin J, Gray DW, Morrison JD. Rehabilitation outcome 5 years after 100 lowerlimb amputations. Br J Surg. 1994;81(11):1596-99.

[PMID:7827880]

http://dx.doi.org/10.1002/bjs. 1800811110

8. Davies B, Datta D. Mobility outcome following unilateral lower limb amputation. Prosthet Orthot Int. 2003;27(3): 186-90. [PMID:14727699] http://dx.doi.org/10.1080/03093640308726681

9. Houghton AD, Taylor PR, Thurlow S, Rootes E, McColl I. Success rates for rehabilitation of vascular amputees: implications for preoperative assessment and amputation level. Br J Surg. 1992;79(8):753-55. [PMID:1393461] http://dx.doi.org/10.1002/bjs.1800790811

10. Sansam K, Neumann V, O’Connor R, Bhakta B. Predicting walking ability following lower limb amputation: a systematic review of the literature. J Rehabil Med. 2009; 41(8):593-603. [PMID:19565152] http://dx.doi.org/10.2340/16501977-0393

11. Geertzen JH, Bosmans JC, van der Schans CP, Dijkstra PU. Claimed walking distance of lower limb amputees. Disabil Rehabil. 2005;27(3):101-4. [PMID:15823990] http://dx.doi.org/10.1080/09638280400009345
12. Narang IC, Mathur BP, Singh P, Jape VS. Functional capabilities of lower limb amputees. Prosthet Orthot Int. 1984;8(1):43-51. [PMID:6718238]

13. Burger H, Marincek C. Functional testing of elderly subjects after lower limb amputation. Prosthet Orthot Int. 2001;25(2):102-7. [PMID:11573876] http://dx.doi.org/10.1080/03093640108726582

14. Moore TJ, Barron J, Hutchinson F 3rd, Golden C, Ellis C, Humphries D. Prosthetic usage following major lower extremity amputation. Clin Orthop Relat Res. 1989;(238): 219-24. [PMID:2910604]

15. Fletcher DD, Andrews KL, Butters MA, Jacobsen SJ, Rowland CM, Hallett JW Jr. Rehabilitation of the geriatric vascular amputee patient: a population-based study. Arch Phys Med Rehabil. 2001;82(6):776-79. [PMID:11387582] http://dx.doi.org/10.1053/apmr.2001.21856

16. Robbins CB, Vreeman DJ, Sothmann MS, Wilson SL, Oldridge NB. A review of the long-term health outcomes associated with war-related amputation. Mil Med. 2009; 174(6):588-92. [PMID:19585770]

17. Norvell DC, Czerniecki JM, Reiber GE, Maynard C, Pecoraro JA, Weiss NS. The prevalence of knee pain and symptomatic knee osteoarthritis among veteran traumatic amputees and nonamputees. Arch Phys Med Rehabil. 2005;86(3):487-93. [PMID:15759233] http://dx.doi.org/10.1016/j.apmr.2004.04.034

18. Kulkarni J, Adams J, Thomas E, Silman A. Association between amputation, arthritis and osteopenia in British male war veterans with major lower limb amputations. Clin Rehabil. 1998;12(4):348-53. [PMID:9744670] http://dx.doi.org/10.1191/026921598672367610

19. Mussman M, Altwerger W, Eisenstein J, Turturro A, Glockenberg A, Bubbers L. Contralateral lower extremity evaluation with a lower limb prosthesis. J Am Podiatry Assoc. 1983;73(7):344-46. [PMID:6875169]

20. Kurdibaylo SF. Obesity and metabolic disorders in adults with lower limb amputation. J Rehabil Res Dev. 1996; 33(4):387-94. [PMID:8895133]

21. Hungerford DS, Cockin J. Fate of the retained lower limb joints in Second World War amputees. Proceedings and reports of universities, colleges, councils, and associations. J Bone Joint Surg Br. 1975;57(B1):111.

22. Hebert JS, Ashworth NL. Predictors of return to work following traumatic work-related lower extremity amputation. Disabil Rehabil. 2006;28(10):613-18. [PMID:16690573] http://dx.doi.org/10.1080/09638280500265219

23. Vrieling AH, van Keeken HG, Schoppen T, Otten E, Halbertsma JP, Hof AL, Postema K. Uphill and downhill walking in unilateral lower limb amputees. Gait Posture. 2008;28(2):235-42. [PMID:18242995] http://dx.doi.org/10.1016/j.gaitpost.2007.12.006 
24. Buckley JG, O'Driscoll D, Bennett SJ. Postural sway and active balance performance in highly active lower-limb amputees. Am J Phys Med Rehabil. 2002;81(1):13-20. [PMID:11807327] http://dx.doi.org/10.1097/00002060-200201000-00004

25. Miller WC, Deathe AB, Speechley M. Psychometric properties of the Activities-specific Balance Confidence Scale among individuals with a lower-limb amputation. Arch Phys Med Rehabil. 2003;84(5):656-61. [PMID:12736877]

26. Miller WC, Deathe AB. A prospective study examining balance confidence among individuals with lower limb amputation. Disabil Rehabil. 2004;26(14-15):875-81. [PMID:15497916] http://dx.doi.org/10.1080/09638280410001708887

27. Miller WC, Speechley M, Deathe B. The prevalence and risk factors of falling and fear of falling among lower extremity amputees. Arch Phys Med Rehabil. 2001;82(8): 1031-37. [PMID:11494181]

http://dx.doi.org/10.1053/apmr.2001.24295

28. Geurts AC, Mulder TH. Attention demands in balance recovery following lower limb amputation. J Mot Behav. 1994;26(2):162-70. [PMID:15753068]

http://dx.doi.org/10.1080/00222895.1994.9941670

29. Fernie GR, Holliday PJ. Postural sway in amputees and normal subjects. J Bone Joint Surg Am. 1978;60(7):895-98. [PMID:701337]

30. Genin JJ, Bastien GJ, Franck B, Detrembleur C, Willems PA. Effect of speed on the energy cost of walking in unilateral traumatic lower limb amputees. Eur J Appl Physiol. 2008;103(6):655-63. [PMID:18478251] http://dx.doi.org/10.1007/s00421-008-0764-0

31. Boonstra AM, Schrama J, Fidler V, Eisma WH. The gait of unilateral transfemoral amputees. Scand J Rehabil Med. 1994;26(4):217-23. [PMID:7878397]

32. Traugh GH, Corcoran PJ, Reyes RL. Energy expenditure of ambulation in patients with above-knee amputations. Arch Phys Med Rehabil. 1975;56(2):67-71. [PMID:1124978]

33. Waters RL, Mulroy S. The energy expenditure of normal and pathologic gait. Gait Posture. 1999;9(3):207-31. [PMID:10575082] http://dx.doi.org/10.1016/S0966-6362(99)00009-0

34. Chin T, Sawamura S, Shiba R, Oyabu H, Nagakura Y, Takase I, Machida K, Nakagawa A. Effect of an Intelligent Prosthesis (IP) on the walking ability of young transfemoral amputees: comparison of IP users with able-bodied people. Am J Phys Med Rehabil. 2003;82(6):447-51. [PMID:12820787] http://dx.doi.org/10.1097/01.PHM.0000069191.20125.38

35. Donker SF, Beek PJ. Interlimb coordination in prosthetic walking: effects of asymmetry and walking velocity. Acta Psychol (Amst). 2002;110(2-3):265-88.

\section{[PMID:12102109]}

http://dx.doi.org/10.1016/S0001-6918(02)00037-9

36. Jaegers SM, Arendzen JH, de Jongh HJ. Prosthetic gait of unilateral transfemoral amputees: a kinematic study. Arch Phys Med Rehabil. 1995;76(8):736-43. [PMID:7632129] http://dx.doi.org/10.1016/S0003-9993(95)80528-1

37. Nolan L, Wit A, Dudziñski K, Lees A, Lake M, Wychowañski $M$. Adjustments in gait symmetry with walking speed in trans-femoral and trans-tibial amputees. Gait Posture. 2003;17(2):142-51. [PMID:12633775] http://dx.doi.org/10.1016/S0966-6362(02)00066-8

38. Hof AL, van Bockel RM, Schoppen T, Postema K. Control of lateral balance in walking. Experimental findings in normal subjects and above-knee amputees. Gait Posture. 2007;25(2):250-58. [PMID:16740390] http://dx.doi.org/10.1016/j.gaitpost.2006.04.013

39. Miller WC, Deathe AB, Speechley M, Koval J. The influence of falling, fear of falling, and balance confidence on prosthetic mobility and social activity among individuals with a lower extremity amputation. Arch Phys Med Rehabil. 2001;82(9):1238-44. [PMID:11552197] http://dx.doi.org/10.1053/apmr.2001.25079

40. Holden JM, Fernie GF. Minimal walking levels for amputees living at home. Physiother Can. 1983;35(6):317-20.

41. Holden JM, Fernie GR. Extent of artificial limb use following rehabilitation. J Orthop Res. 1987;5(4):562-68. [PMID:3681530] http://dx.doi.org/10.1002/jor.1100050411

42. Stepien JM, Cavenett S, Taylor L, Crotty M. Activity levels among lower-limb amputees: self-report versus step activity monitor. Arch Phys Med Rehabil. 2007;88(7): 896-900. [PMID:17601471] http://dx.doi.org/10.1016/j.apmr.2007.03.016

43. Ramstrand N, Nilsson KA. A comparison of foot placement strategies of transtibial amputees and able-bodied subjects during stair ambulation. Prosthet Orthot Int. 2009;33(4):348-55. [PMID:19961296] http://dx.doi.org/10.3109/03093640903074891

44. Vrieling AH, van Keeken HG, Schoppen T, Otten E, Halbertsma JP, Hof AL, Postema K. Obstacle crossing in lower limb amputees. Gait Posture. 2007;26(4):587-94. [PMID:17275306] http://dx.doi.org/10.1016/j.gaitpost.2006.12.007

45. Jones SF, Twigg PC, Scally AJ, Buckley JG. The mechanics of landing when stepping down in unilateral lowerlimb amputees. Clin Biomech (Bristol, Avon). 2006; 21(2):184-93. [PMID:16274904] http://dx.doi.org/10.1016/j.clinbiomech.2005.09.015

46. Geurts AC, Mulder TW, Nienhuis B, Rijken RA. Dualtask assessment of reorganization of postural control in persons with lower limb amputation. Arch Phys Med Rehabil. 1991;72(13):1059-64. [PMID:1741657] 
47. Nakamura R, Moriai N, Sajiki N. Reaction times of normal subjects and amputees with below-knee and aboveknee prostheses during stepping. Prosthet Orthot Int. 1984;8(2):100-102. [PMID:6483588]

48. Dougherty PJ. Long-term follow-up of unilateral transfemoral amputees from the Vietnam war. J Trauma. 2003; 54(4):718-23. [PMID:12707534] http://dx.doi.org/10.1097/01.TA.0000046260.16866.A9

49. Hagberg K, Brånemark R. Consequences of non-vascular trans-femoral amputation: a survey of quality of life, prosthetic use and problems. Prosthet Orthot Int. 2001;25(3): 186-94. [PMID:11860092]

50. Legro MW, Reiber G, del Aguila M, Ajax MJ, Boone DA, Larsen JA, Smith DG, Sangeorzan B. Issues of importance reported by persons with lower limb amputations and prostheses. J Rehabil Res Dev. 1999;36(3):155-63. [PMID:10659798]

51. Pezzin LE, Dillingham TR, MacKenzie EJ. Rehabilitation and the long-term outcomes of persons with traumarelated amputations. Arch Phys Med Rehabil. 2000; 81(3):292-300. [PMID:10724073] http://dx.doi.org/10.1016/S0003-9993(00)90074-1

52. Ware JE Jr, Sherbourne CD. The MOS 36-item Shortform Health Survey (SF-36). I. Conceptual framework and item selection. Med Care. 1992;30(6):473-83.

[PMID:1593914]

http://dx.doi.org/10.1097/00005650-199206000-00002

53. Sullivan M, Karlsson J, Ware JE Jr. SF-36 hälsoenkät: svensk manual och tolkningsguide (Swedish manual and interpretation guide). Göteborg (Sweden): Sahlgrenska University Hospital; 1994. Swedish.

54. Kelly BM, Spires MC, Restrepo JA. Orthotic and prosthetic prescriptions for today and tomorrow. Phys Med Rehabil Clin N Am. 2007;18(4):785-858, vii. [PMID:17967365] http://dx.doi.org/10.1016/j.pmr.2007.08.001

55. Friel K. Componentry for lower extremity prostheses. J Am Acad Orthop Surg. 2005;13(5):326-35. [PMID:16148358]

56. Cochrane H, Orsi K, Reilly P. Lower limb amputation. Part 3: Prosthetics - a 10 year literature review. Prosthet Orthot Int. 2001;25(1):21-28. [PMID:11411001] http://dx.doi.org/10.1080/03093640108726564

57. Pasquina PF, Bryant PR, Huang ME, Roberts TL, Nelson VS, Flood KM. Advances in amputee care. Arch Phys Med Rehabil. 2006;87(3 Suppl 1):S34-43, quiz S44-45. [PMID:16500191]

58. Tang PC, Ravji K, Key JJ, Mahler DB, Blume PA, Sumpio B. Let them walk! Current prosthesis options for leg and foot amputees. J Am Coll Surg. 2008;206(3):548-60. [PMID:18308228] http://dx.doi.org/10.1016/j.jamcollsurg.2007.10.007
59. Michael JW. Modern prosthetic knee mechanisms. Clin Orthop Relat Res. 1999;(361):39-47. [PMID:10212594]

60. van de Veen PG. Above-knee prosthesis technology. Enschede (the Netherlands): P. G. van de Veen Consultancy; 2001.

61. Romo HD. Prosthetic knees. Phys Med Rehabil Clin N Am. 2000;11(3):595-607, vii. [PMID:10989481]

62. Berry D. Microprocessor prosthetic knees. Phys Med Rehabil Clin N Am. 2006;17(1):91-113, vii. [PMID:16517347] http://dx.doi.org/10.1016/j.pmr.2005.10.006

63. Zahedi S. The results of the field trial of the Endolite Intelligent Prosthesis. Proceedings of the 12th International Congress of INTERBOR; 1993 Sep 22-25; Lisbon, Portugal.

64. Armstrong EC. The well-built clinical question: the key to finding the best evidence efficiently. WMJ. 1999;98(2): 25-28. [PMID:10235058]

65. Schlosser RW, Koul R, Costello J. Asking well-built questions for evidence-based practice in augmentative and alternative communication. J Commun Disord. 2007;40(3): 225-38. [PMID:16876187] http://dx.doi.org/10.1016/j.jcomdis.2006.06.008

66. Scherer S, Smith MB. Research corner: Teaching evidence-based practice in academic and clinical settings. Cardiopulm Phys Ther J. 2002;13(2):23-27.

67. Portney LG, Watkins MP. Foundations of clinical research: Applications to practice. 3rd ed. Upper Saddle River (NJ): Pearson/Prentice Hall; 2009.

68. Huang CT, Jackson JR, Moore NB, Fine PR, Kuhlemeier KV, Traugh GH, Saunders PT. Amputation: energy cost of ambulation. Arch Phys Med Rehabil. 1979;60(1):18-24. [PMID:420566]

69. Su PF, Gard SA, Lipschutz RD, Kuiken TA. Gait characteristics of persons with bilateral transtibial amputations. J Rehabil Res Dev. 2007;44(4):491-501. [PMID:18247246] http://dx.doi.org/10.1682/JRRD.2006.10.0135

70. Tsai HA, Kirby RL, MacLeod DA, Graham MM. Aided gait of people with lower-limb amputations: comparison of 4-footed and 2-wheeled walkers. Arch Phys Med Rehabil. 2003;84(4):584-91. [PMID:12690599] http://dx.doi.org/10.1053/apmr.2003.50079

71. Hafner BJ. State-of-the-science evidence report guidelines. Washington (DC): American Academy of Orthotists and Prosthetists; 2008.

72. Hafner BJ, Smith DG. Differences in function and safety between Medicare Functional Classification Level-2 and -3 transfemoral amputees and influence of prosthetic knee joint control. J Rehabil Res Dev. 2009;46(3):417-33.

[PMID:19675993] http://dx.doi.org/10.1682/JRRD.2008.01.0007

73. Hafner BJ, Willingham LL, Buell NC, Allyn KJ, Smith DG. Evaluation of function, performance, and preference 
as transfemoral amputees transition from mechanical to microprocessor control of the prosthetic knee. Arch Phys Med Rehabil. 2007;88(2):207-17. [PMID:17270519] http://dx.doi.org/10.1016/j.apmr.2006.10.030

74. Sanders JE, Fatone S. Residual limb volume change: systematic review of measurement and management. J Rehabil Res Dev. 2011;48(8):949-86. [PMID:22068373] http://dx.doi.org/10.1682/JRRD.2010.09.0189

75. Buckley JG, Spence WD, Solomonidis SE. Energy cost of walking: comparison of "intelligent prosthesis" with conventional mechanism. Arch Phys Med Rehabil. 1997; 78(3):330-33. [PMID:9084360] http://dx.doi.org/10.1016/S0003-9993(97)90044-7

76. Datta D, Heller B, Howitt J. A comparative evaluation of oxygen consumption and gait pattern in amputees using Intelligent Prostheses and conventionally damped knee swing-phase control. Clin Rehabil. 2005;19(4):398-403. [PMID:15929508] http://dx.doi.org/10.1191/0269215505cr805oa

77. Jepson F, Datta D, Harris I, Heller B, Howitt J, McLean J. A comparative evaluation of the Adaptive knee and Catech knee joints: a preliminary study. Prosthet Orthot Int. 2008;32(1):84-92. [PMID:18330807] http://dx.doi.org/10.1080/03093640701676376

78. Johansson JL, Sherrill DM, Riley PO, Bonato P, Herr H. A clinical comparison of variable-damping and mechanically passive prosthetic knee devices. Am J Phys Med Rehabil. 2005;84(8):563-75. [PMID:16034225] http://dx.doi.org/10.1097/01.phm.0000174665.74933.0b

79. Kaufman KR, Levine JA, Brey RH, McCrady SK, Padgett DJ, Joyner MJ. Energy expenditure and activity of transfemoral amputees using mechanical and microprocessorcontrolled prosthetic knees. Arch Phys Med Rehabil. 2008;89(7):1380-85. [PMID:18586142] http://dx.doi.org/10.1016/j.apmr.2007.11.053

80. Kirker S, Keymer S, Talbot J, Lachmann S. An assessment of the intelligent knee prosthesis. Clin Rehabil. 1996;10: 267-73. http://dx.doi.org/10.1177/026921559601000314

81. Orendurff MS, Segal AD, Klute GK, McDowell ML, Pecoraro JA, Czerniecki JM. Gait efficiency using the C-Leg. J Rehabil Res Dev. 2006;43(2):239-46. [PMID:16847790] http://dx.doi.org/10.1682/JRRD.2005.06.0095

82. Schmalz T, Blumentritt S, Jarasch R. Energy expenditure and biomechanical characteristics of lower limb amputee gait: the influence of prosthetic alignment and different prosthetic components. Gait Posture. 2002;16(3):255-63. [PMID:12443950] http://dx.doi.org/10.1016/S0966-6362(02)00008-5

83. Seymour R, Engbretson B, Kott K, Ordway N, Brooks G, Crannell J, Hickernell E, Wheeler K. Comparison between the C-leg microprocessor-controlled prosthetic knee and non-microprocessor control prosthetic knees: a prelimi- nary study of energy expenditure, obstacle course performance, and quality of life survey. Prosthet Orthot Int. 2007;31(1):51-61. [PMID:17365885] http://dx.doi.org/10.1080/03093640600982255

84. Taylor MB, Clark E, Offord EA, Baxter C. A comparison of energy expenditure by a high level trans-femoral amputee using the Intelligent Prosthesis and conventionally damped prosthetic limbs. Prosthet Orthot Int. 1996;20(2): 116-21. [PMID:8876005]

85. Lifson N, Gordon GB, McClintock R. Measurement of total carbon dioxide production by means of D2O18. J Appl Physiol. 1955;7(6):704-10. [PMID:14381351]

86. Butler P, Engelbrecht M, Major RE, Tait JH, Stallard J, Patrick JH. Physiological cost index of walking for normal children and its use as an indicator of physical handicap. Dev Med Child Neurol. 1984;26(5):607-12. [PMID:6239799] http://dx.doi.org/10.1111/j.1469-8749.1984.tb04499.x

87. Borg GA. Psychophysical bases of perceived exertion. Med Sci Sports Exerc. 1982;14(5):377-81.

[PMID:7154893] http://dx.doi.org/10.1249/00005768-198205000-00012

88. Datta D, Howitt J. Conventional versus microchip controlled pneumatic swing phase control for trans-femoral amputees: user's verdict. Prosthet Orthot Int. 1998;22(2): 129-35. [PMID:9747997]

89. Gerzeli S, Torbica A, Fattore G. Cost utility analysis of knee prosthesis with complete microprocessor control (C-leg) compared with mechanical technology in trans-femoral amputees. Eur J Health Econ. 2009;10(1):47-55.

[PMID:18379831] http://dx.doi.org/10.1007/s10198-008-0102-9

90. Kahle JT, Highsmith MJ, Hubbard SL. Comparison of nonmicroprocessor knee mechanism versus C-Leg on Prosthesis Evaluation Questionnaire, stumbles, falls, walking tests, stair descent, and knee preference. J Rehabil Res Dev. 2008;45(1):1-14. [PMID:18566922] http://dx.doi.org/10.1682/JRRD.2007.04.0054

91. Klute GK, Berge JS, Orendurff MS, Williams RM, Czerniecki JM. Prosthetic intervention effects on activity of lower-extremity amputees. Arch Phys Med Rehabil. 2006;87(5):717-22. [PMID:16635636] http://dx.doi.org/10.1016/j.apmr.2006.02.007

92. Seelen H, Hemmen B, Schmeets A, Ament A, Evers S. Cost and consequences of a prosthesis with an electronically stance and swing phase controlled knee joint. Technol Disabil. 2009;21:25-34.

93. Coleman KL, Smith DG, Boone DA, Joseph AW, del Aguila MA. Step activity monitor: long-term, continuous recording of ambulatory function. J Rehabil Res Dev. 1999;36(1):8-18. [PMID:10659890]

94. Williams RM, Turner AP, Orendurff M, Segal AD, Klute GK, Pecoraro J, Czerniecki J. Does having a computerized 
prosthetic knee influence cognitive performance during amputee walking? Arch Phys Med Rehabil. 2006; 87(7): 989-94. [PMID:16813788]

http://dx.doi.org/10.1016/j.apmr.2006.03.006

95. Heller BW, Datta D, Howitt J. A pilot study comparing the cognitive demand of walking for transfemoral amputees using the Intelligent Prosthesis with that using conventionally damped knees. Clin Rehabil. 2000;14(5):518-22.

[PMID:11043877]

http://dx.doi.org/10.1191/0269215500cr345oa

96. Herr H, Wilkenfeld A. User-adaptive control of a magnetorheological prosthetic knee. Ind Rob. 2003;30(1):42-55. http://dx.doi.org/10.1108/01439910310457706

97. Kaufman KR, Levine JA, Brey RH, Iverson BK, McCrady SK, Padgett DJ, Joyner MJ. Gait and balance of transfemoral amputees using passive mechanical and microprocessor-controlled prosthetic knees. Gait Posture. 2007;26(4):489-93. [PMID:17869114] http://dx.doi.org/10.1016/j.gaitpost.2007.07.011

98. Segal AD, Orendurff MS, Klute GK, McDowell ML, Pecoraro JA, Shofer J, Czerniecki JM. Kinematic and kinetic comparisons of transfemoral amputee gait using C-Leg and Mauch SNS prosthetic knees. J Rehabil Res Dev. 2006;43(7):857-70. [PMID:17436172] http://dx.doi.org/10.1682/JRRD.2005.09.0147

99. Yokogushi K, Narita H, Uchiyama E, Chiba S, Nosaka T, Yamakoshi K. Biomechanical and clinical evaluation of a newly designed polycentric knee of transfemoral prosthesis. J Rehabil Res Dev. 2004;41(5):675-82. [PMID:15558397] http://dx.doi.org/10.1682/JRRD.2003.05.0076

100. Pelland L, McKinley P. The Montreal rehabilitation performance profile: a task-analysis approach to quantify stair descent performance in children with intellectual disability. Arch Phys Med Rehabil. 2001;82(8):1106-14. [PMID:11494191] http://dx.doi.org/10.1053/apmr.2001.24225

101. Berry D, Olson MD, Larntz K. Perceived stability, function and satisfaction among transfemoral amputees using microprocessor and nonmicroprocessor controlled prosthetic knees: a multicenter survey. J Prosthet Orthot. 2009; 21(1):32-42.

102. Blumentritt S, Schmalz T, Jarasch R. The safety of C-leg: Biomechanical tests. J Prosthet Orthot. 2009;21(1):2-17.

103. Stevens PM, Carson R. Case report: Using the Activitiesspecific Balance Confidence scale to quantify the impact of prosthetic knee choice on balance confidence. J Prosthet Orthot. 2007;19(4):114-16.

104. Nashner LM. Computerized dynamic posturography. In: Jacobson GP, Newman CW, Kartush JM, editors. Handbook of balance function testing. St. Louis (MO): Mosby Year Book; 1993. p. 280-305.
105. Brodtkorb TH, Henriksson M, Johannesen-Munk K, Thidell F. Cost-effectiveness of C-leg compared with non-microprocessor-controlled knees: a modeling approach. Arch Phys Med Rehabil. 2008;89(1):24-30. [PMID:18164326] http://dx.doi.org/10.1016/j.apmr.2007.07.049

106. EuroQol - a new facility for the measurement of healthrelated quality of life. The EuroQol Group. Health Policy. 1990;16(3):199-208. [PMID:10109801] http://dx.doi.org/10.1016/0168-8510(90)90421-9

107. Law MC. Evidence-based rehabilitation: A guide to practice. Thorofare (NJ): Slack; 2002.

108. Fatone S. A review of the literature pertaining to KAFO and HKAFOs for ambulation. J Prosthet Orthot. 2006;18(7): P137-68.

109. Neumann ES. State-of-the-science review of transtibial prosthesis alignment perturbation. J Prosthet Orthot. 2009; 21(4):175-93.

110. Dillon MP, Fatone S, Hodge MC. Biomechanics of ambulation after partial foot amputation: A systematic literature review. Alexandria (VA): American Academy of Orthotists and Prosthetists; 2007.

111. Condie E, Scott H, Treweek S. Lower limb prosthetic outcome measures: a review of the literature 1995 to 2005. J Prosthet Orthot. 2006;18(6):P13-45.

112. Wright V. Prosthetic outcome measures for use with upper limb amputees: A systematic review of the peer-reviewed literature, 1970 to 2009. J Prosthet Orthot. 2009;21(9):P3-P63.

113. Hofstad C, Linde H, Limbeek J, Postema K. Prescription of prosthetic ankle-foot mechanisms after lower limb amputation. Cochrane Database Syst Rev. 2004;(1): CD003978. [PMID:14974050]

114. van der Linde H, Hofstad CJ, Geurts AC, Postema K, Geertzen JH, van Limbeek J. A systematic literature review of the effect of different prosthetic components on human functioning with a lower-limb prosthesis. J Rehabil Res Dev. 2004;41(4):555-70. [PMID:15558384] http://dx.doi.org/10.1682/JRRD.2003.06.0102

115. Gitter A, Czerniecki J, Weaver K. A reassessment of center-of-mass dynamics as a determinate of the metabolic inefficiency of above-knee amputee ambulation. Am J Phys Med Rehabil. 1995;74(5):332-38. [PMID:7576408] http://dx.doi.org/10.1097/00002060-199509000-00002

116. Hoffman MD, Sheldahl LM, Buley KJ, Sandford PR. Physiological comparison of walking among bilateral above-knee amputee and able-bodied subjects, and a model to account for the differences in metabolic cost. Arch Phys Med Rehabil. 1997;78(4):385-92. [PMID:9111458] http://dx.doi.org/10.1016/S0003-9993(97)90230-6

117. Waters RL, Perry J, Antonelli D, Hislop H. Energy cost of walking of amputees: the influence of level of amputation. J Bone Joint Surg Am. 1976;58(1):42-46. [PMID:1249111] 
118. Weyand PG, Smith BR, Sandell RF. Assessing the metabolic cost of walking: the influence of baseline subtractions. Conf Proc IEEE Eng Med Biol Soc. 2009;2009: 6878-81. [PMID:19964188]

119. Armstrong LE, Costil DL. Variability of respiration and metabolism: responses to submaximal cycling and running. Res Q Exerc Sport. 1985;56(2):93-96.

120. Parvataneni K, Ploeg L, Olney SJ, Brouwer B. Kinematic, kinetic and metabolic parameters of treadmill versus overground walking in healthy older adults. Clin Biomech (Bristol, Avon). 2009;24(1):95-100. [PMID:18976839] http://dx.doi.org/10.1016/j.clinbiomech.2008.07.002

121. Brouwer B, Parvataneni K, Olney SJ. A comparison of gait biomechanics and metabolic requirements of overground and treadmill walking in people with stroke. Clin Biomech (Bristol, Avon). 2009;24(9):729-34. [PMID:19664866] http://dx.doi.org/10.1016/j.clinbiomech.2009.07.004

122. Traballesi M, Porcacchia P, Averna T, Brunelli S. Energy cost of walking measurements in subjects with lower limb amputations: a comparison study between floor and treadmill test. Gait Posture. 2008;27(1):70-75. [PMID:17360186] http://dx.doi.org/10.1016/j.gaitpost.2007.01.006

123. Melanson EL Jr, Freedson PS. Physical activity assessment: a review of methods. Crit Rev Food Sci Nutr. 1996; 36(5):385-96. [PMID:8725670] http://dx.doi.org/10.1080/10408399609527732

124. Kuo AD. The six determinants of gait and the inverted pendulum analogy: A dynamic walking perspective. Hum Mov Sci. 2007;26(4):617-56. [PMID:17617481] http://dx.doi.org/10.1016/j.humov.2007.04.003

125. Kuo AD, Donelan JM. Dynamic principles of gait and their clinical implications. Phys Ther. 2010;90(2):157-74. [PMID:20023002] http://dx.doi.org/10.2522/ptj.20090125

126. Chin T, Machida K, Sawamura S, Shiba R, Oyabu H, Nagakura Y, Takase I, Nakagawa A. Comparison of different microprocessor controlled knee joints on the energy consumption during walking in trans-femoral amputees: intelligent knee prosthesis (IP) versus C-leg. Prosthet Orthot Int. 2006;30(1):73-80. [PMID:16739783] http://dx.doi.org/10.1080/03093640500533414

127. Christensen B, Ellegaard B, Bretler U, Ostrup EL. The effect of prosthetic rehabilitation in lower limb amputees. Prosthet Orthot Int. 1995;19(1):46-52. [PMID:7617458]

128. Burger H, Marincek C, Isakov E. Mobility of persons after traumatic lower limb amputation. Disabil Rehabil. 1997;19(7):272-77. [PMID:9246543] http://dx.doi.org/10.3109/09638289709166538

129. Pring DJ, Marks L, Angel JC. Mobility after amputation for failed knee replacement. J Bone Joint Surg Br. 1988; 70(5):770-71. [PMID:3192577]
130. Cavanaugh JT, Kochi N, Stergiou N. Nonlinear analysis of ambulatory activity patterns in community-dwelling older adults. J Gerontol A Biol Sci Med Sci. 2010;65(2): 197-203. [PMID:19822625] http://dx.doi.org/10.1093/gerona/glp144

131. Amputee Coalition of America. First step: A guide for adapting to limb loss. Knoxville (TN): Amputee Coalition of America; 2004.

132. Tudor-Locke C, Burkett L, Reis JP, Ainsworth BE, Macera CA, Wilson DK. How many days of pedometer monitoring predict weekly physical activity in adults? Prev Med. 2005;40(3):293-98. [PMID:15533542] http://dx.doi.org/10.1016/j.ypmed.2004.06.003

133. Clemes SA, Griffiths PL. How many days of pedometer monitoring predict monthly ambulatory activity in adults? Med Sci Sports Exerc. 2008;40(9):1589-95. [PMID:18685533] http://dx.doi.org/10.1249/MSS.0b013e318177eb96

134. Kang M, Bassett DR, Barreira TV, Tudor-Locke C, Ainsworth B, Reis JP, Strath S, Swartz A. How many days are enough? A study of 365 days of pedometer monitoring. Res Q Exerc Sport. 2009;80(3):445-53. [PMID:19791630] http://dx.doi.org/10.5641/027013609X13088500159129

135. Togo F, Watanabe E, Park H, Yasunaga A, Park S, Shephard RJ, Aoyagi Y. How many days of pedometer use predict the annual activity of the elderly reliably? Med Sci Sports Exerc. 2008;40(6):1058-64. [PMID:18461001] http://dx.doi.org/10.1249/MSS.0b013e318167469a

136. Demet K, Martinet N, Guillemin F, Paysant J, André JM. Health related quality of life and related factors in 539 persons with amputation of upper and lower limb. Disabil Rehabil. 2003;25(9):480-86. [PMID:12745943] http://dx.doi.org/10.1080/0963828031000090434

137. Pell JP, Donnan PT, Fowkes FG, Ruckley CV. Quality of life following lower limb amputation for peripheral arterial disease. Eur J Vasc Surg. 1993;7(4):448-51. [PMID:8359304] http://dx.doi.org/10.1016/S0950-821X(05)80265-8

138. Zidarov D, Swaine B, Gauthier-Gagnon C. Quality of life of persons with lower-limb amputation during rehabilitation and at 3-month follow-up. Arch Phys Med Rehabil. 2009;90(4):634-45. [PMID:19345780] http://dx.doi.org/10.1016/j.apmr.2008.11.003

139. Patel SN, Truong KN, Abowd GD. PowerLine Positioning: A practical sub-room-level indoor location system for domestic use. Berlin (Germany): Springer-Verlag; 2006.

140. Kiani K, Snijders CJ, Gelsema ES. Recognition of daily life motor activity classes using an artificial neural network. Arch Phys Med Rehabil. 1998;79(2):147-54. [PMID:9473995] http://dx.doi.org/10.1016/S0003-9993(98)90291-X 
141. Aziz W, Arif M. Complexity analysis of stride interval time series by threshold dependent symbolic entropy. Eur J Appl Physiol. 2006;98(1):30-40. [PMID:16841202] http://dx.doi.org/10.1007/s00421-006-0226-5

142. Geurts AC, Mulder TW, Rijken RA, Nienhuis B. From the analysis of movements to the analysis of skills. J Rehabil Sci. 1991;4(1):9-12.

143. Abernethy B, Hanna A, Plooy A. The attentional demands of preferred and non-preferred gait patterns. Gait Posture. 2002;15(3):256-65. [PMID:11983500] http://dx.doi.org/10.1016/S0966-6362(01)00195-3

144. Alexander NB, Ashton-Miller JA, Giordani B, Guire K, Schultz AB. Age differences in timed accurate stepping with increasing cognitive and visual demand: a walking trail making test. J Gerontol A Biol Sci Med Sci. 2005; 60(12):1558-62. [PMID:16424288] http://dx.doi.org/10.1093/gerona/60.12.1558

145. Pellecchia GL. Postural sway increases with attentional demands of concurrent cognitive task. Gait Posture. 2003; 18(1):29-34. [PMID:12855298] http://dx.doi.org/10.1016/S0966-6362(02)00138-8

146. Bunce DJ, Breakey JW. The impact of C-Leg on the physical and psychological adjustment to transfemoral amputation. J Prosthet Orthot. 2007;19(1):7-14.

147. Kerr B, Condon SM, McDonald LA. Cognitive spatial processing and the regulation of posture. J Exp Psychol Hum Percept Perform. 1985;11(5):617-22. [PMID:2932533] http://dx.doi.org/10.1037/0096-1523.11.5.617

148. Meier MR, Hansen AH, Gard SA. Performance on an obstacle course: Otto Bock C-Leg vs. Otto Bock 3R60 vs. CaTech SNS. Proceedings of the 31st Annual Meeting and Scientific Symposium of the American Academy of Orthotists and Prosthetists (AAOP) and the Association of the Children's Prosthetic-Orthotic Clinics (ACPOC); 2005 Feb 27-Mar 1; Orlando, FL.

149. Lajoie Y, Teasdale N, Bard C, Fleury M. Attentional demands for static and dynamic equilibrium. Exp Brain Res. 1993;97(1):139-44. [PMID:8131825] http://dx.doi.org/10.1007/BF00228824

150. Perry J. Gait analysis: Normal and pathological function. Thorofare (NJ): SLACK; 1992.

151. Pinzur MS, Gold J, Schwartz D, Gross N. Energy demands for walking in dysvascular amputees as related to the level of amputation. Orthopedics. 1992;15(9): 1033-36, discussion 1036-37. [PMID:1437862]

152. Schmid M, Beltrami G, Zambarbieri D, Verni G. Centre of pressure displacements in trans-femoral amputees during gait. Gait Posture. 2005;21(3):255-62. [PMID:15760740] http://dx.doi.org/10.1016/j.gaitpost.2004.01.016

153. Sulzle H, Pagliarulo M, Rodgers M, Jordan C. Energetics of amputee gait. Orthop Clin North Am. 1978;9(2):358-62. [PMID:662299]
154. Kulkarni J, Gaine WJ, Buckley JG, Rankine JJ, Adams J. Chronic low back pain in traumatic lower limb amputees. Clin Rehabil. 2005;19(1):81-86. [PMID:15704512] http://dx.doi.org/10.1191/0269215505cr819oa

155. Gailey R, Allen K, Castles J, Kucharik J, Roeder M. Review of secondary physical conditions associated with lower-limb amputation and long-term prosthesis use. J Rehabil Res Dev. 2008;45(1):15-29. [PMID:18566923] http://dx.doi.org/10.1682/JRRD.2006.11.0147

156. Lemaire ED, Fisher FR. Osteoarthritis and elderly amputee gait. Arch Phys Med Rehabil. 1994;75(10):1094-99. [PMID:7944914]

157. Willingham LL, Buell NC, Allyn KJ, Hafner BJ, Smith DG. Measurement of knee center alignment trends in a national sample of established users of the Otto Bock C-leg microprocessor-controlled knee unit. J Prosthet Orthot. 2004; 16(3):72-75.

158. Sjödahl C, Jarnlo GB, Söderberg B, Persson BM. Kinematic and kinetic gait analysis in the sagittal plane of trans-femoral amputees before and after special gait reeducation. Prosthet Orthot Int. 2002;26(2):101-12. [PMID:12227444] http://dx.doi.org/10.1080/03093640208726632

159. Sawers AB, Hahn ME. The potential for error with use of inverse dynamic calculations in gait analysis of individuals with lower limb loss: a review of model selection and assumptions. J Prosthet Orthot. 2010;22(1):56-61.

160. Bergmann JH, Mayagoitia RE, Smith IC. A portable system for collecting anatomical joint angles during stair ascent: a comparison with an optical tracking device. Dyn Med. 2009;8:3. [PMID:19389238] http://dx.doi.org/10.1186/1476-5918-8-3

161. Mayagoitia RE, Nene AV, Veltink PH. Accelerometer and rate gyroscope measurement of kinematics: an inexpensive alternative to optical motion analysis systems. J Biomech. 2002;35(4):537-42. [PMID:11934425] http://dx.doi.org/10.1016/S0021-9290(01)00231-7

162. Geertzen JH. Moving beyond disability. Prosthet Orthot Int. 2008;32(3):276-81. [PMID:18609035] http://dx.doi.org/10.1080/03093640802067061

163. Zahedi MS, Spence WD, Solomonidis SE, Paul JP. Alignment of lower-limb prostheses. J Rehabil Res Dev. 1986; 23(2):2-19. [PMID:3723422]

164. Yang L, Solomonidis SE, Spence WD, Paul JP. The influence of limb alignment on the gait of above-knee amputees. J Biomech. 1991;24(11):981-97. [PMID:1761584] http://dx.doi.org/10.1016/0021-9290(91)90016-G

165. Blumentritt S, Scherer HW, Michael JW, Schmalz T. Transfemoral amputees walking on a rotary hydraulic prosthetic knee mechanism: a preliminary report. J Prosthet Orthot. 1998;10(3):61-70. 
166. Breakey JW. Theory of integrated balance: the lower limb amputee. J Prosthet Orthot. 1998;10(2):42-44.

167. Cohen JJ, Sveen JD, Walker JM, Brummel-Smith K. Establishing criteria for community ambulation. Top Geriatr Rehabil. 1987;3(1):71-78.

168. Lerner-Frankiel MB, Vargas S, Brown M, Krusell L, Schoneberger W. Functional community ambulation: what are your criteria? Clin Manag Phys Ther. 1986;6(2):12-15.

169. Medicare region $\mathrm{C}$ durable medical equipment prosthetics orthotic supplier (DMEPOS) manual. Columbia (SC): Palmetto GBA; 2005.

170. Bae TS, Choi K, Mun M. Level walking and stair climbing gait in above-knee amputees. J Med Eng Technol. 2009;33(2):130-35. [PMID:19205992] http://dx.doi.org/10.1080/03091900701404043

171. Bae TS, Choi K, Hong D, Mun M. Dynamic analysis of above-knee amputee gait. Clin Biomech (Bristol, Avon). 2007;22(5):557-66. [PMID:17321021]

http://dx.doi.org/10.1016/j.clinbiomech.2006.12.009

172. Schmalz T, Blumentritt S, Marx B. Biomechanical analysis of stair ambulation in lower limb amputees. Gait Posture. 2007;25(2):267-78. [PMID:16725325] http://dx.doi.org/10.1016/j.gaitpost.2006.04.008

173. MacKenzie EJ, Bosse MJ, Castillo RC, Smith DG, Webb LX, Kellam JF, Burgess AR, Swiontkowski MF, Sanders RW, Jones AL, McAndrew MP, Patterson BM, Travison TG, McCarthy ML. Functional outcomes following traumarelated lower-extremity amputation. J Bone Joint Surg Am. 2004;86-A(8):1636-45. [PMID:15292410]

174. Buell NC, Willingham LL, Allyn KJ, Hafner BJ, Smith DG. Evaluation of gait style to ascend and descend stairs for lower limb amputees. Proceedings of the 11th World Congress of the International Society for Prosthetics and Orthotics; 2004 Aug 1-6; Hong Kong.

175. Buell NC, Willingham LL, Allyn KJ, Hafner BJ, Smith DG. Evaluation of gait style for hill descent for lower limb amputees. Proceedings of the 11th World Congress of the International Society for Prosthetics and Orthotics; 2004 Aug 1-6; Hong Kong.

176. McFadyen BJ, Winter DA. An integrated biomechanical analysis of normal stair ascent and descent. J Biomech. 1988;21(9):733-44. [PMID:3182877] http://dx.doi.org/10.1016/0021-9290(88)90282-5

177. Perron M, Malouin F, Moffet H. Assessing advanced locomotor recovery after total hip arthroplasty with the timed stair test. Clin Rehabil. 2003;17(7):780-86. [PMID:14606746]

http://dx.doi.org/10.1191/0269215503cr696oa

178. Held SL, Kott KM, Young BL. Standardized Walking Obstacle Course (SWOC): reliability and validity of a new functional measurement tool for children. Pediatr
Phys Ther. 2006;18(1):23-30. [PMID:16508531]

http://dx.doi.org/10.1097/01.pep.0000202251.79000.1d

179. Means KM. The obstacle course: a tool for the assessment of functional balance and mobility in the elderly. J Rehabil Res Dev. 1996;33(4):413-29. [PMID:8895137]

180. Vrieling AH, van Keeken HG, Schoppen T, Otten E, Hof AL, Halbertsma JP, Postema K. Balance control on a moving platform in unilateral lower limb amputees. Gait Posture. 2008;28(2):222-28. [PMID:18207407] http://dx.doi.org/10.1016/j.gaitpost.2007.12.002

181. Gauthier-Gagnon C, Grisé MC, Potvin D. Enabling factors related to prosthetic use by people with transtibial and transfemoral amputation. Arch Phys Med Rehabil. 1999; 80(6):706-13. [PMID:10378500]

http://dx.doi.org/10.1016/S0003-9993(99)90177-6

182. Ganz DA, Higashi T, Rubenstein LZ. Monitoring falls in cohort studies of community-dwelling older people: effect of the recall interval. J Am Geriatr Soc. 2005;53(12): 2190-94. [PMID:16398908]

http://dx.doi.org/10.1111/j.1532-5415.2005.00509.x

183. Lamb SE, Jørstad-Stein EC, Hauer K, Becker C; Prevention of Falls Network Europe and Outcomes Consensus Group. Development of a common outcome data set for fall injury prevention trials: the Prevention of Falls Network Europe consensus. J Am Geriatr Soc. 2005;53(9): 1618-22. [PMID:16137297] http://dx.doi.org/10.1111/j.1532-5415.2005.53455.x

184. Bourke AK, van de Ven PW, Chaya AE, OLaighin GM, Nelson J. Testing of a long-term fall detection system incorporated into a custom vest for the elderly. Conf Proc IEEE Eng Med Biol Soc. 2008;2008:2844 47. [PMID:19163298] http://dx.doi.org/10.1109/IEMBS.2008.4649795

185. Kang DW, Choi JS, Lee JW, Chung SC, Park SJ, Tack GR. Real-time elderly activity monitoring system based on a tri-axial accelerometer. Disabil Rehabil Assist Technol. 2010;5(4):247-53. [PMID:20302417] http://dx.doi.org/10.3109/17483101003718112

186. Nguyen TT, Cho MC, Lee TS. Automatic fall detection using wearable biomedical signal measurement terminal. Conf Proc IEEE Eng Med Biol Soc. 2009;2009:5203-6. [PMID:19964661] http://dx.doi.org/10.1109/IEMBS.2009.5334079

187. Zahedi S, Sykes A, Lang S, Cullington I. Adaptive prosthesis - a concept in prosthetic knee control. Robotica. 2005;23(3):337-44. http://dx.doi.org/10.1017/S0263574704001365

188. Van der Linde H, Hofstad CJ, Geertzen JH, Postema K, Van Limbeek J. From satisfaction to expectation: the patient's perspective in lower limb prosthetic care. Disabil Rehabil. 2007;29(13):1049-55. [PMID:17612990] http://dx.doi.org/10.1080/09638280600948375 
189. Dillingham TR, Pezzin LE, MacKenzie EJ, Burgess AR. Use and satisfaction with prosthetic devices among persons with trauma-related amputations: a long-term outcome study. Am J Phys Med Rehabil. 2001;80(8):563-71. [PMID:11475475]

http://dx.doi.org/10.1097/00002060-200108000-00003

190. Gauthier-fiagnon C, Grise M, Potvin D. Predisposing factors related to prosthetic use by people with a transtibial and transfemoral amputation. J Prosthet Orthot. 1998; 10(4):99-109.

191. Pezzin LE, Dillingham TR, Mackenzie EJ, Ephraim P, Rossbach P. Use and satisfaction with prosthetic limb devices and related services. Arch Phys Med Rehabil. 2004;85(5):723-29. [PMID:15129395] http://dx.doi.org/10.1016/j.apmr.2003.06.002

192. Nielsen CC, Psonak RA, Kalter TL. Factors affecting the use of prosthetic services. J Prosthet Orthot. 1989;1(4): 242-49.

193. Schaffalitzky E, NiMhurchadha S, Gallagher P, Hofkamp S, MacLachlan M, Wegener ST. Identifying the values and preferences of prosthetic users: a case study series using the repertory grid technique. Prosthet Orthot Int. 2009;33(2):157-66. [PMID:19367519] http://dx.doi.org/10.1080/03093640902855571

194. Heinemann AW, Bode RK, O’Reilly C. Development and measurement properties of the Orthotics and Prosthetics Users' Survey (OPUS): a comprehensive set of clinical outcome instruments. Prosthet Orthot Int. 2003;27(3): 191-206. [PMID:14727700] http://dx.doi.org/10.1080/03093640308726682

195. Bilodeau S, Hébert R, Desrosiers J. [Questionnaire on the satisfaction of persons with lower-limb amputations towards their prosthesis: development and validation]. Can J Occup Ther. 1999;66(1):23-32. French. [PMID:10462879]

196. Gallagher P, MacLachlan M. Development and psychometric evaluation of the Trinity Amputation and Prosthesis Experience Scales (TAPES). Rehabil Psychol. 2000; 45(2): 130-54. http://dx.doi.org/10.1037/0090-5550.45.2.130

197. Hart DL. Orthotics and Prosthetics National Outcomes Tool (OPOT): initial reliability and validity assessment for lower extremity prosthetics. J Prosthet Orthot. 1999; 11(4):101-11.

198. Fisher K, Hanspal R. Body image and patients with amputations: does the prosthesis maintain the balance? Int J Rehabil Res. 1998;21(4):355-63. [PMID:9926350] http://dx.doi.org/10.1097/00004356-199812000-00002

199. Marriott M. Titanium and sensor replace Ahab's peg leg. The New York Times. 2005.

200. Schaffer E, Kort C, Kreuter P. The prosthetic knee microprocessor and non-microprocessor knee joints. In Motion. 2008 Nov-Dec.
201. Stone PW. Using economic evidence in clinical practice. J Med Pract Manage. 2002;17(5):272-77. [PMID:12024866]

202. Russell LB, Gold MR, Siegel JE, Daniels N, Weinstein $\mathrm{MC}$; Panel on Cost-Effectiveness in Health and Medicine. The role of cost-effectiveness analysis in health and medicine. JAMA. 1996;276(14):1172-77. [PMID:8827972] http://dx.doi.org/10.1001/jama.1996.03540140060028

203. Eichler HG, Kong SX, Gerth WC, Mavros P, Jönsson B. Use of cost-effectiveness analysis in health-care resource allocation decision-making: how are cost-effectiveness thresholds expected to emerge? Value Health. 2004;7(5): 518-28. [PMID:15367247] http://dx.doi.org/10.1111/j.1524-4733.2004.75003.x

204. McDowell I, Newell C. Measuring health: A guide to rating scales and questionnaires. 2nd ed. New York (NY): Oxford University Press; 1996.

205. Wood-Dauphinee S. Assessing quality of life in clinical research: from where have we come and where are we going? J Clin Epidemiol. 1999;52(4):355-63. [PMID:10235176] http://dx.doi.org/10.1016/S0895-4356(98)00179-6

206. Asano M, Rushton P, Miller WC, Deathe BA. Predictors of quality of life among individuals who have a lower limb amputation. Prosthet Orthot Int. 2008;32(2):231-43. [PMID:18569891] http://dx.doi.org/10.1080/03093640802024955

207. Deans SA, McFadyen AK, Rowe PJ. Physical activity and quality of life: A study of a lower-limb amputee population. Prosthet Orthot Int. 2008;32(2):186-200. [PMID:18569887] http://dx.doi.org/10.1080/03093640802016514

208. Legro MW, Reiber GD, Smith DG, del Aguila M, Larsen J, Boone D. Prosthesis evaluation questionnaire for persons with lower limb amputations: assessing prosthesisrelated quality of life. Arch Phys Med Rehabil. 1998; 79(8):931-38. [PMID:9710165] http://dx.doi.org/10.1016/S0003-9993(98)90090-9

209. Finch E; Canadian Physiotherapy Association. Physical rehabilitation outcome measures: A guide to enhanced clinical decision making. 2nd ed. Baltimore (MD): Lippincott Williams and Wilkins; 2002.

210. Staniszewska S. Patient expectations and health-related quality of life. Health Expect. 1999;2(2):93-104.

[PMID:11281883] http://dx.doi.org/10.1046/j.1369-6513.1999.00046.x

211. Callaghan BG, Condie ME. A post-discharge quality of life outcome measure for lower limb amputees: test-retest reliability and construct validity. Clin Rehabil. 2003; 17(8):858-64. [PMID:14682557] http://dx.doi.org/10.1191/0269215503cr689oa 
212. Rushton PW, Miller WC. Goal attainment scaling in the rehabilitation of patients with lower-extremity amputations: a pilot study. Arch Phys Med Rehabil. 2002;83(6):

771-75. [PMID:12048654] http://dx.doi.org/10.1053/apmr.2002.32636

213. Highsmith MJ, Kahle JT, Bongiorni DR, Sutton BS, Groer S, Kaufman KR. Safety, energy efficiency, and cost efficacy of the C-Leg for transfemoral amputees: A review of the literature. Prosthet Orthot Int. 2010;34(4): 362-77. [PMID:20969495] http://dx.doi.org/10.3109/03093646.2010.520054

214. Mâaref K, Martinet N, Grumillier C, Ghannouchi S, André JM, Paysant J. Kinematics in the terminal swing phase of unilateral transfemoral amputees: microprocessor-controlled versus swing-phase control prosthetic knees. Arch Phys Med Rehabil. 2010;91(6):919-25. [PMID:20510984] http://dx.doi.org/10.1016/j.apmr.2010.01.025

215. Theeven P, Hemmen B, Rings F, Meys G, Brink P, Smeets R, Seelen H. Functional added value of microprocessorcontrolled knee joints in daily life performance of Medicare Functional Classification Level-2 amputees. J Rehabil Med. 2011;43(10):906-15. [PMID:21947182]

216. Theeven P, Hemmen B, Stevens C, Ilmer E, Brink P, Seelen $\mathrm{H}$. Feasibility of a new concept for measuring actual functional performance in daily life of transfemoral amputees. J Rehabil Med. 2010;42(8):744-51. [PMID:20809056] http://dx.doi.org/10.2340/16501977-0591

217. Atkins D, Eccles M, Flottorp S, Guyatt GH, Henry D, Hill S, Liberati A, O'Connell D, Oxman AD, Phillips B, Schünemann H, Edejer TT, Vist GE, Williams JW Jr; GRADE
Working Group. Systems for grading the quality of evidence and the strength of recommendations I: critical appraisal of existing approaches The GRADE Working Group. BMC Health Serv Res. 2004;4(1):38. [PMID:15615589] http://dx.doi.org/10.1186/1472-6963-4-38

218. Higgins JP, Green S; Cochrane Collaboration. Cochrane handbook for systematic reviews of interventions. Hoboken (NJ): Wiley-Blackwell; 2008.

219. Tonelli MR. Integrating evidence into clinical practice: an alternative to evidence-based approaches. J Eval Clin Pract. 2006;12(3):248-56. [PMID:16722902] http://dx.doi.org/10.1111/j.1365-2753.2004.00551.x

220. Sackett DL. Evidence-based medicine: how to practice and teach EBM. 2nd ed. New York (NY): Churchill Livingstone; 2000.

Submitted for publication October 5, 2011. Accepted in revised form July 24, 2012.

This article and any supplementary material should be cited as follows:

Sawers AB, Hafner BJ. Outcomes associated with the use of microprocessor-controlled prosthetic knees among individuals with unilateral transfemoral limb loss: A systematic review. J Rehabil Res Dev. 2013;50(3):273-314. http://dx.doi.org/10.1682/JRRD.2011.10.0187

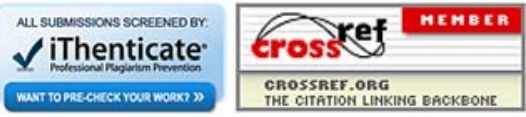

